\title{
Manipulations of Central Amygdala Neurotensin Neurons Alter the Consumption of Ethanol and Sweet Fluids in Mice
}

\author{
(-)María Luisa Torruella-Suárez, ${ }^{1,2}$ Jessica R. Vandenberg, ${ }^{2}$ Elizabeth S. Cogan, ${ }^{2}$ Gregory J. Tipton, ${ }^{2}$ Adonay Teklezghi, ${ }^{2}$ \\ Kedar Dange, ${ }^{2}$ Gunjan K. Patel, ${ }^{2}$ Jenna A. McHenry, ${ }^{3,4}$ J. Andrew Hardaway, ${ }^{2,5}$ Pranish A. Kantak, ${ }^{3}$ Nicole A. Crowley, ${ }^{1,2}$ \\ Jeffrey F. DiBerto, ${ }^{2,5}$ Sara P. Faccidomo, ${ }^{2}$ Clyde W. Hodge, ${ }^{2,3}$ Garret D. Stuber, ${ }^{2,3,4}$ and @Zoé A. McElligott ${ }^{2,3,5}$ \\ ${ }^{1}$ Neuroscience Curriculum, ${ }^{2}$ Bowles Center for Alcohol Studies, ${ }^{3}$ Department of Psychiatry, ${ }^{4}$ Neuroscience Center, and ${ }^{5}$ Department of Pharmacology, \\ University of North Carolina at Chapel Hill, Chapel Hill, North Carolina, 27599
}

The central nucleus of the amygdala plays a significant role in alcohol use and other affective disorders; however, the genetically-defined neuronal subtypes and projections that govern these behaviors are not well known. Here we show that neurotensin neurons in the central nucleus of the amygdala of male mice are activated by in vivo ethanol consumption and that genetic ablation of these neurons decreases ethanol consumption and preference in non-ethanol-dependent animals. This ablation did not impact preference for sucrose, saccharin, or quinine. We found that the most robust projection of the central amygdala neurotensin neurons was to the parabrachial nucleus, a brain region known to be important in feeding behaviors, conditioned taste aversion, and alarm. Optogenetic stimulation of projections from these neurons to the parabrachial nucleus is reinforcing, and increases ethanol drinking as well as consumption of sucrose and saccharin solutions. These data suggest that this central amygdala to parabrachial nucleus projection influences the expression of reward-related phenotypes and is a novel circuit promoting consumption of ethanol and palatable fluids.

Key words: alcohol; central nucleus of the amygdala; consumption; ethanol; parabrachial nucleus; reward

Significance Statement

Alcohol use disorder (AUD) is a major health burden worldwide. Although ethanol consumption is required for the development of AUD, much remains unknown regarding the underlying neural circuits that govern initial ethanol intake. Here we show that ablation of a population of neurotensin-expressing neurons in the central amygdala decreases intake of and preference for ethanol in non-dependent animals, whereas the projection of these neurons to the parabrachial nucleus promotes consumption of ethanol as well as other palatable fluids.

\section{Introduction}

The central nucleus of the amygdala (CeA) is a heterogeneous structure that plays an important role in the regulation of appetitive, aversive, and ethanol-mediated behaviors (Mahler and Berridge, 2009; Tye et al., 2011; Robinson et al., 2014; McCall et al., 2015; Salling et al., 2016; Douglass et al., 2017; Kim et al., 2017;

\footnotetext{
Received June 21, 2019; revised Oct. 11, 2019; accepted Nov. 4, 2019.

Author contributions: M.L.T.-S., G.J.T., C.W.H., G.D.S., and Z.A.M. designed research; M.L.T.-S., J.R.V., E.S.C., G.J.T., A.T., K.D., G.K.P., J.A.M., J.A.H., P.A.K., N.A.C., J.F.D., S.P.F., and Z.A.M. performed research;Z.A.M. contributed unpublished reagents/analytic tools; M.L.T.-S., J.R.V., E.S.C., G.J.T., A.T., K.D., G.K.P., J.A.M., J.A.H., P.K., N.C., S.P.F., and Z.A.M. analyzed data; M.L.T.-S. and Z.A.M. wrote the paper.

This work was supported by: K01AA023555 (Z.A.M.), 550 KR71419 (Z.A.M.), P60 AA011605 (C.W.H., G.D.S), R37AA014983 (C.W.H.), F31AA026183 (M.L.T.-S.), T32 NS007431 (M.L.T.-S), U01 AA020911 (Z.A.M.), U24 AA025475 (Z.A.M.), K01DK115902 (J.A.H.), DK056350 Nutrition Obesity Research Center Pilot and Feasibility Award (Z.A.M.), and the Alcohol Beverage Medical Research Foundation (Z.A.M.) We thank Drs. Thomas Kash, Karl T. Schmidt, and Elyse Dankoski, as well as Madigan Lavery for comments on previous versions of the paper.

The authors declare no competing financial interests.

Correspondence should be addressed to Zoé A. McElligott at zoemce@email.unc.edu.

https://doi.org/10.1523/JNEUROSCI.1466-19.2019

Copyright $\odot 2020$ the authors
}

Warlow et al., 2017; Hardaway et al., 2019). Although some data have shed light on neuronal subpopulations influencing fear- and feeding-related behaviors in the CeA (Haubensak et al., 2010; Cai et al., 2014; Douglass et al., 2017), it remains unclear which CeA subpopulations and efferents influence ethanol consumption, particularly during early ethanol seeking (Gilpin et al., 2015; de Guglielmo et al., 2019). A promising CeA subpopulation that may regulate ethanol behaviors are the neurons that express the 13 amino-acid neuropeptide neurotensin (NTS).

NTS is expressed throughout the mammalian brain, including but not limited to the lateral hypothalamus (LH), amygdala, hippocampus, and rostral medulla (Schroeder et al., 2019). Considerable evidence suggests that NTS signaling is critical for reward and anxiety processes (Cáceda et al., 2006; Leinninger et al., 2011; Fitzpatrick et al., 2012; Prus et al., 2014; McHenry et al., 2017), and global manipulations of NTS signaling disrupt ethanolrelated phenotypes (Lee et al., 2010, 2011). However, the roles of individual NTS-positive (NTS+) neuronal populations are not well understood, as the majority of studies investigating NTS + 
cells have focused on the LH to ventral tegmental area pathway, and particularly on NTS/dopamine interactions (Binder et al., 2001; Leinninger et al., 2011; Kempadoo et al., 2013; McHenry et al., 2017). NTS + neurons in the CeA (NTS ${ }^{\mathrm{CeA}}$ ) have yet to be extensively studied and are in a compelling anatomical and functional position to influence ethanol consumption. Furthermore, early studies identified NTS ${ }^{\mathrm{CeA}}$ cells that project to the parabrachial nucleus (PBN; Moga and Gray, 1985), a brain region important for fluid consumption.

The PBN, a heterogeneous nucleus that has long been recognized as a sensory relay for taste information, plays a crucial role in the development of conditioned taste aversion (Grigson et al., 1998; Carter et al., 2015). Interestingly, intraperitoneal injections of ethanol induce Fos activation in the PBN (Chang et al., 1995; Thiele et al., 1996). This suggests that the PBN may either be a direct locus for the pharmacological effects of ethanol, and/or receive information regarding the interoception of ethanol. The PBN is also linked to general fluid intake (Edwards and Johnson, 1991) and recent work has identified the PBN oxytocin receptor (Oxtr1)-containing neurons as an important locus for fluid satiation (Ryan et al., 2017). An additional subpopulation of PBN neurons, the calcitonin gene-related peptide (CGRP) neurons, are part of an important circuit implicated in suppressing both food and fluid intake (Carter et al., 2013; Ryan et al., 2017). An Htr2a CeA-to-PBN (serotonin receptor $2 \mathrm{a}, \mathrm{Htr} 2 a^{\mathrm{CeA} \rightarrow \mathrm{PBN}}$ ) projection promotes feeding, suggesting the possibility of a CeA-toPBN projection that promotes drinking (Douglass et al., 2017). A number of systems have been suggested as a link between food and ethanol consumption such as neuropeptide-Y (Kelley et al., 2001; Gilpin et al., 2004) and ghrelin (Leggio, 2010). Fluid consumption-related circuits, however, have yet to be examined in this fashion.

To investigate the complex relationship between the CeA and $\mathrm{PBN}$, and better understand the role of the NTS ${ }^{\mathrm{CeA}}$ neuronal subpopulation in ethanol consumption and appetitive behaviors, we used NTS-IRES-Cre mice (Leinninger et al., 2011) in conjunction with region-directed genetic lesion, Fos activation, terminal field optogenetic stimulation, and behavioral assays. We find that NTS ${ }^{\mathrm{CeA}}$ neurons are activated by, and promote ethanol consumption. Furthermore, stimulation of the NTS ${ }^{\mathrm{CeA} \rightarrow \mathrm{PBN}}$ projection is reinforcing, and increases the consumption of palatable fluids such as ethanol, sucrose, and saccharin solutions, without altering consumption of neutral or aversive fluids. These data implicate the NTS ${ }^{\mathrm{CeA} \rightarrow \mathrm{PBN}}$ circuit as a critical node for the consumption of rewarding and/or palatable fluids.

\section{Materials and Methods}

Subjects, stereotaxic surgery, virus injection and fiber implantation Mice. All procedures were conducted in accordance with the Guide for the Care and Use of Laboratory Animals, as adopted by the $\mathrm{NIH}$, and with approval of an Institutional Animal Care and Use Committee at UNCChapel Hill. Adult male mice 10 weeks and older $(>22 \mathrm{~g})$ were used for all experiments. C57BL/6J mice were used for the in situ tastant exposure experiment (Jackson Laboratories). We used adult male NTS-IRES-Cre mice (Leinninger et al., 2011) partially backcrossed onto a C57BL/6J background for all other experiments (Jackson Laboratories). Animals were maintained on a reverse $12 \mathrm{~h}$ light cycle with lights off at 7:00 A.M. and had ad libitum access to food and water (unless noted).

Surgery. Mice were anesthetized with inhaled isoflurane (1-3\%) and placed in a stereotaxic frame (David Kopf). For all experiments coordinates for the CeA were as follows (from bregma, in mm: ML: \pm 2.95 , AP: $-1.1, \mathrm{DV}:-4.8$, for the PBN: ML \pm 1.4 , AP: $-5.4, \mathrm{DV}:-4.0$ (optical fibers). $300 \mathrm{nl}$ of AAV5-Ef1 $\alpha$-FLEX-taCasp3-TEVp (denoted as $\mathrm{CeA}^{\text {NTS }}:$ :casp), AAV5-Ef1 $\alpha$-ChR2-eYFP (denoted as NTS::ChR2 or
NTS $\left.{ }^{\mathrm{CeA} \rightarrow \mathrm{PBN}}:: \mathrm{ChR} 2\right), \quad$ AAV8-eF1a-DIO-iC ++ -eYFP (denoted as

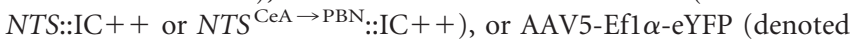

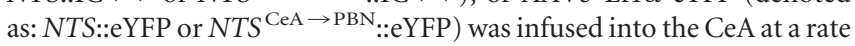
of $100 \mathrm{nl} / \mathrm{min}$. Optical fibers were constructed as previously described (Sparta et al., 2011). Mice were allowed to recover for at least 4 weeks before experimentation ( 8 weeks for optogenetic experiments) to ensure adequate expression of virally encoded genes, and lesioning of target neurons, or protein incorporation into the membrane. All viruses were made by the UNC Viral Vector Core (Chapel Hill, NC) or the Stanford Viral Vector (Palo Alto, CA). Following behavioral studies, animals with ChR2-eYFP construct were perfused, and brains were sliced to verify expression of virus. Animals with no viral expression in either CeA were removed $(n=1)$, while animals with either bilateral or unilateral viral expression were included in the analysis as our pilot data indicated that unilateral expression of the virus was sufficient to drive real-time place preference (RTPP) behavior (data not shown). Animals expressing the caspase construct were killed, and brains were flash frozen for validation using fluorescent in situ hybridization (FISH; see the following section) and compared with their eYFP controls.

\section{Fluorescent in situ hybridization}

CeA transcript expression. Mice were anesthetized (isoflurane), decapitated, and brains were flash frozen on dry ice. $12 \mu \mathrm{m}$ slices were made using a Leica cryostat (CM 3050S). FISH was performed using probes constructed against Crh, Crhrl, Pdyn (type-6, fast blue) and Nts (type 1, fast red) and reagents in the View RNA kit (Affymetrix). FISH was also performed for Fos (Mm-Fos-C1, Mm-Fos-C2), Sst (Mm-Sst-C2), Pkc $\delta$ (Mm-Prkcd-C2), and Nts (Mm-Nts-C1, Mm-Nts-C2) using the RNAscope Fluorescent Multiplex Assay (Advanced Cell Diagnostics). Slides were counterstained with DAPI.

In vivo tastant exposure. Singly-housed C57BL/6J mice were habituated to the animal facility for at least 2 weeks. Each animal had home-cage access to a single bottle of either water, $6 \%(\mathrm{w} / \mathrm{v})$ ethanol, $1 \%(\mathrm{w} / \mathrm{v})$ sucrose, $0.003 \%(\mathrm{w} / \mathrm{v})$ saccharin, or $100 \mu \mathrm{M}$ quinine for $2 \mathrm{~h}$ for 4 consecutive days. On the fifth day, animals had $1 \mathrm{~h}$ of exposure to the same bottle. Half an hour after the bottle was removed, the animals were killed for Nts/Fos double FISH using RNAscope Fluorescent Multiplex Assay (Advanced Cell Diagnostics). CeA slices were taken from approximately bregma -0.8 to $-1.9 \mathrm{~mm}$. Experimenters were blinded to consumption conditions for Fos and Nts counting.

\section{Immunohistochemistry}

As previously described (Pleil et al., 2015), mice were perfused with $4 \%$ paraformaldehyde (in $0.01 \mathrm{~m}$ PBS), brains were removed and remained in fixative for $24 \mathrm{~h}$ followed by cryoprotection in $30 \%$ sucrose/PBS. Subsequently brains were sliced at $40 \mu \mathrm{m}$ using either a CM 3050S or a VT1000 (Leica). Sections were incubated overnight at $4^{\circ} \mathrm{C}$ in blocking solution containing primary antibody: sheep anti-tyrosine hydroxylase 1:500 (Pel Freeze), rabbit anti-neurotensin 1:500 (ab43833, Abcam). The following day, sections were incubated in fluorescence-conjugated donkey anti-rabbit IgG AlexaFluor 647 secondary antibody (1:800; Jackson ImmunoResearch) and donkey anti-sheep 488 (1:200; Invitrogen) for $2 \mathrm{~h}$ in darkness. 435 NeuroTrace or DAPI was used as a counterstain.

\section{Microscopy}

Images were collected and processed on a Zeiss 710,780 , or 800 a using $20 \times / 0.8$ objective and the Zen software (Carl Zeiss). ImageJ/Fiji was used for cell counting and data analysis.

\section{Slice preparation and whole-cell electrophysiology}

As previously described (Pleil et al., 2015), animals were anesthetized (isoflurane or pentobarbital/phenytoin) and decapitated. Brains were removed and sliced at a thickness of $200 \mu \mathrm{m}(\mathrm{CeA}$ or PBN) or $300 \mu \mathrm{m}$ (CeA) using a Leica VT1200 or VT1000 in ice-cold high-sucrose low $\mathrm{Na}^{+}$ artificial CSF (aCSF; in mm: 194 sucrose, $20 \mathrm{NaCl}, 4.4 \mathrm{KCl}, 2 \mathrm{CaCl}_{2}, 1$ $\mathrm{MgCl}_{2}, 1.2 \mathrm{NaH}_{2} \mathrm{PO}_{4}, 10$ glucose, $26 \mathrm{NaHCO}_{3}$ ) that had been oxygenated $\left(95 \% \mathrm{O}_{2}, 5 \% \mathrm{CO}_{2}\right)$ for a minimum of $15 \mathrm{~min}$. Following slicing, brains were allowed to equilibrate in normal aCSF (in mM: $124 \mathrm{NaCl}, 4.4 \mathrm{KCl}, 2$ $\mathrm{CaCl}_{2}, 1.2 \mathrm{MgSO}_{4}, 1 \mathrm{NaH}_{2} \mathrm{PO}_{4}, 10$ glucose, $26 \mathrm{NaHCO}_{3}, 34^{\circ} \mathrm{C}$ ) for at least $30 \mathrm{~min}$. Next, slices were transferred to the recording chamber and 
allowed to equilibrate in oxygenated aCSF $\left(28-30^{\circ} \mathrm{C}\right)$ perfused at $2 \mathrm{ml} /$ min for an additional $30 \mathrm{~min}$. Recordings examining cell excitability were performed in current-clamp using K-gluconate intracellular recording solution (in mM: K-gluconate $135, \mathrm{NaCl} 5, \mathrm{MgCl}_{2} 2$, HEPES 10, EGTA $0.6, \mathrm{Na}_{2} \mathrm{ATP} 4, \mathrm{Na}_{2} \mathrm{GTP} 0.4$ ). Recordings examining synaptic currents were performed with either in $\mathrm{CsCl}$ intracellular solution (in $\mathrm{mm}$ : 130 CsCl, 1 EGTA, 10 HEPES, 2 ATP, 0.2 GTP) or Cs-methanesulfonate (in mM: 117 Cs methanesulfonic acid, 20 HEPES, 0.4 EGTA, $2.8 \mathrm{NaCl}, 5$ TEA, 2 ATP, 0.2 GTP) intracellular solutions. CsCl recordings were conducted in kynurenic acid ( $3 \mathrm{~mm}$ ) to block glutamatergic currents. Ex vivo ChR2 stimulation for whole-cell recording was performed using an 470 nм LED from Thorlabs or CoolLED.

\section{Blood ethanol content}

Blood ethanol content (BEC) was measured by administering a dose of $2.0 \mathrm{~g} / \mathrm{kg}$ ( $20 \%$ ethanol w/v, i.p.). Mice were restrained ( $<2 \mathrm{~min})$ in Plexiglas tubes (Braintree Scientific) and a scalpel was used to make a small nick in the mouse tail. Blood was collected in a heparinized capillary tube at 30 and $60 \mathrm{~min}$ following the injection. The plasma was removed and analyzed for BEC using an Analox-G-5 analyzer (Analox Instruments).

\section{Home-cage drinking paradigms}

Two-bottle choice. In their home cage, mice were given $24 \mathrm{~h}$ access to a bottle containing a test fluid and a bottle of water. The concentration of the test fluid escalated over the course of the experiment at $3 \mathrm{~d} / \mathrm{dose}$. These solutions were ethanol $(3,6,10 \% \mathrm{w} / \mathrm{v}$, unsweetened), sucrose $(0.1$, $0.3,1,2,3 \% \mathrm{w} / \mathrm{v})$, saccharin $(0.003,0.001,0.03,0.1 \% \mathrm{w} / \mathrm{v})$, and quinine $(1,3,10,30,100,300 \mu \mathrm{M})$. We weighed the bottles every $24 \mathrm{~h}$ and switched the side of the cage where the test bottle was located daily. We report these data as the average drinking values for each mouse averaged over the course of the $3 \mathrm{~d}$.

Intermittent access. Intermittent access (IA) was performed as described by Hwa et al. (2011). Briefly, mice had access to both a bottle of $20 \%(\mathrm{w} / \mathrm{v})$ ethanol (unsweetened), and water in their home cage on Monday, Wednesday, and Friday. On other days, they only had access to two bottles of water. Bottles were rotated with each exposure to ensure that animals did not associate ethanol or water with a particular side of the cage.

\section{Locomotor and anxiety assays}

All locomotor and anxiety assays were performed using EthoVision XT tracking software (Noldus Information Technology) to measure location, distance moved, and velocity.

$R T P P$. Mice were placed in an apparatus $(50 \times 50 \times 25 \mathrm{~cm})$ that was divided down the middle with a door for exploration on both sides, and which had no distinguishing features on either side. For $20 \mathrm{~min}$, mice were allowed to explore the apparatus and received optical stimulation $(20 \mathrm{~Hz}$ for the ChR2 animals, and constant stimulation for the IC ++ animals, $473 \mathrm{~nm}, 10 \mathrm{~mW}$, Arduino UNO, or Master 8, AMP Instruments) on one side (counterbalanced) and no stimulation on the other side.

oICSS. First cohort: NTS ${ }^{\mathrm{CeA} \rightarrow \mathrm{PBN}}:: \mathrm{ChR} 2(n=14)$ and control $(n=$ 11) mice were food-restricted to $80 \%$ of their normal food intake for $2 \mathrm{~d}$ before optical intracranial self-stimulation (oICSS). They were tethered to the laser and placed in the chamber $(15.9 \mathrm{~cm} \times 14.0 \mathrm{~cm} \times 12.7 \mathrm{~cm}$; Med Associates) for $1 \mathrm{~h}$. Both nose ports (active and inactive) were baited with a very small amount of their normal feed to encourage exploration. A dim house light flashed when the animal poked the active port along with $5 \mathrm{~s}$ of stimulation during which time further pokes had no effect (20 or $40 \mathrm{~Hz}, 473 \mathrm{~nm}, 10 \mathrm{~mW}$ ).

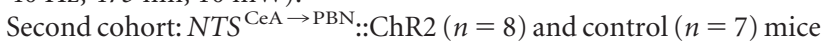
were not food restricted and ports were baited with a small amount of Froot Loops (Kellogg's). Mice that were fed ad libitum did not exhibit reduced motivation to poke for stimulation; therefore, we collapsed the data across cohorts.

Open field. Mice were allowed to explore the open field $(50 \times 50 \mathrm{~cm})$ for $30 \mathrm{~min}$ where distance traveled and velocity were measured (EthoVision).
Light/dark box. Mice were placed into the dark enclosed side of the apparatus (Med Associates) and time spent in the light side and entries to the light were monitored for $15 \mathrm{~min}$ (EthoVision).

Elevated plus maze. Mice were placed in the center of the apparatus at the beginning of the test. NTS ${ }^{\mathrm{CeA}}$ ::casp and control mice were given 5 min to explore the open arm, closed arm, and center portion of the maze, and time spent in arms, center, and number of entries were monitored.

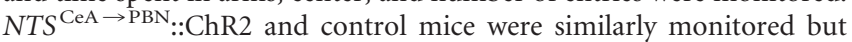
given $5 \mathrm{~min}$ to explore the maze without stimulation, $5 \mathrm{~min}$ with stimulation $(20 \mathrm{~Hz}, 473 \mathrm{~nm}, 10 \mathrm{~mW})$ and an additional $5 \mathrm{~min}$ without stimulation (EthoVision).

Marble burying. Twelve marbles were placed on a $5 \mathrm{~cm}$ deep layer of corncob bedding in a standard size mouse cage $(39 \times 20 \times 16 \mathrm{~cm})$ in a grid-like fashion. Mice were then placed in the cage for $30 \mathrm{~min}$ and the degree of marble burying was hand-scored. If a marble was $>1 / 2$ buried it was considered buried. The experimenter was blinded to the viral treatment group before the experiment.

Novelty-suppressed feeding. Mice were singly-housed 1 week before testing. Forty-eight hours before testing, animals were allowed to consume a Froot Loop in their home cage. Food was then removed from the home cage for $24 \mathrm{~h}$. Mice were then placed in a corner of an open field $(26.7 \times 48.3 \mathrm{~cm})$ at the center of which we placed a single Froot Loop on filter paper. Latency to feed was measured as the time required for the mouse to begin consuming the Froot Loop. If the mouse had not approached the fruit loop after $10 \mathrm{~min}$, it was removed from the open field and scored as $10 \mathrm{~min}$. Immediately following, the mouse was returned to its home cage and allowed to freely consume Froot Loops for $10 \mathrm{~min}$. If the mouse did not consume any Froot Loops in the home cage, it was not included for this measurement.

\section{Optical stimulation consumption paradigm}

Mice were habituated to EthoVision Phenotyper boxes (Noldus) over the course of $4 \mathrm{~d}$ for $3 \mathrm{~h}$ each. Mice were tethered to the optical commutator, and had access to a bottle of the test fluid and normal chow throughout the habituation period. Over the subsequent $4 \mathrm{~d}$, mice were placed in the same boxes, again with their standard mouse chow and the test fluid in a bottle with a Lick-O-Meter (Noldus) attached. The mice received either optical stimulation across $3 \mathrm{~h}(473 \mathrm{~nm}, 20 \mathrm{~Hz}, 10 \mathrm{~mW}, 5 \mathrm{~min}$ on-off cycles; see Fig. 9A), or no stimulation (counterbalanced) for within animal comparison (repeated measures two-way ANOVA). Stimulation was delivered in a noncontingent fashion, to avoid pairing any particular part of the chamber with the stimulation and producing an RTPP-like effect as seen in Figure $8 D$. The test fluids were water, $6 \%(\mathrm{w} / \mathrm{v})$ ethanol, $1 \%$ $(\mathrm{w} / \mathrm{v})$ sucrose, $0.003 \%(\mathrm{w} / \mathrm{v})$ saccharine, and $100 \mu \mathrm{m}$ quinine.

\section{Statistical analysis}

Data are presented as mean \pm SEM. Significance is presented as ${ }^{*} p<$ $0.05,{ }^{* *} p<0.01,{ }^{* * *} p<0.001,{ }^{* * * *} p<0.0001$. All statistical analyses were performed using GraphPad Prism v6.02 for Windows. For the Fos/ Nts in situ experiment, comparisons were planned between the ethanol and water groups based on the results from the experiments in the caspase drinking studies. Following that, we performed one-way ANOVAs with Dunnett's post hoc tests (referred to as Dunn's post hoc test in Prism) using the water group as the control group. In the caspase experiments we used a Student's $t$ test. Optogenetic behavioral data were subjected to a matched two-way ANOVA were applicable, followed by post hoc Bonferroni-corrected $t$ tests if a significant interaction was detected. Where ANOVAs were not applicable, the data were subjected to a Student's $t$ test. Data are reported as the mean \pm SEM. The fluid consumption values for the FISH experiment were reported as SD to convey variability in the drinking.

One NTS ${ }^{\mathrm{CeA}}:$ :eYFP (control) animal was removed from the caspase drinking studies due to extremely low ethanol consumption. It consumed not $<2.1 \mathrm{~g} / \mathrm{kg}$ ethanol average per week and its preference for ethanol was $>2$ SD from the mean for control animals. One NTS ${ }^{\mathrm{CeA} \rightarrow \mathrm{PBN}}:: \mathrm{ChR} 2$ was removed from the water-drinking phenotyper experiment. Stimulation-day drinking for this mouse was a ROUT outlier from all other water-drinking days (stim and non-stim,

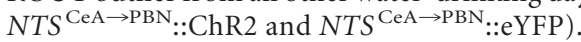



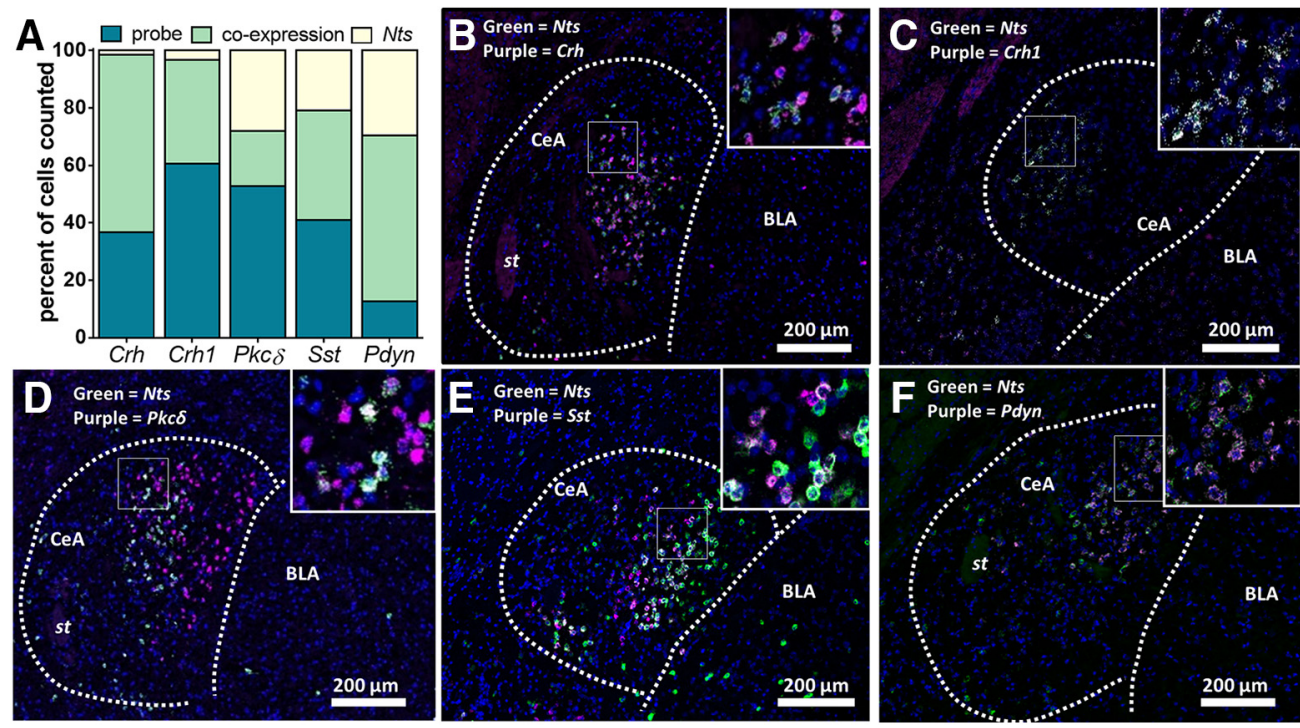

Figure 1. Nts neurons in the CeA express a variety of markers. A, Quantification of dual FISH in the CeA for Nts colocalization with Crh, Crh1, Pkc $\delta$, Sst, and Pdyn. B-F, Representative confocal images with Nts (green), probe (purple), and DAPI (blue). B. Ninety-eight percent of Nts neurons expressed C $r h$, and $37 \%$ of Crh expressed Nts ( $n=3$ mice, $5-6$ slices/mouse). C, Ninety-two percent of Nts neurons expressed Crh1 and 63\% of Crh1 expressed Nts ( $n=4$ mice, 5- 6 slices/mouse). D, Forty-one percent of Nts expressed Pkc $\delta$ and $27 \%$ of Pkc $\delta$ neurons expressing Nts $(n=4$ mice, $2-4$ slices/mouse). $\boldsymbol{E}$, Sixty-five percent of Nts expressed Sst and $48 \%$ of Sst neurons expressing Nts ( $n=4$ mice, $2-4$ slices/mouse). $\boldsymbol{F}$, Forty-eight percent of Nts expressed Pdyn and $82 \%$ of $P d y n$ neurons expressed Nts ( $n=4$ mice, 5-6 slices/mouse; green, Nts; purple, probe; blue, DAPI). st, Stria terminalis; BLA, basolateral amygdala. Scale bars, $200 \mu \mathrm{m}$.

\section{Results}

\section{NTS neurons in the CeA express a variety of markers}

We first explored how Nts-expressing neurons overlap with other previously described genetically-defined populations in the CeA. Using dual FISH across the entire CeA, we examined neuronal overlap with cells expressing mRNA for corticotropin releasing hormone [also known as corticotropin releasing factor $(\mathrm{Crh})$ ], corticotropin-releasing hormone receptor 1 [also known as CRF receptor $1(C r h r 1)]$, preprodynorphin $(P d y n)$, protein kinase $\mathrm{C}$ delta $(P k c \delta)$, and somatostatin $(S s t)$. We found that CeA Ntsexpressing neurons largely express Crh and Crh1 (Fig. 1). Surprisingly, we found that one-third of CeA Nts neurons express $P k c \delta$, a population that has been reported to have limited overlap with CeA Crh cells (Cai et al., 2014). One-third of Nts CeA neurons express $S$ st, a population that has been implicated in the switch between passive and active stress coping mechanisms (Yu et al., 2016). Last, $\sim$ two-thirds of CeA-NTS labeled neurons also express $P d y n$, the precursor of the endogenous ligand for the $\kappa$ opioid receptor, dynorphin (Chavkin et al., 1982).

\footnotetext{
Ablation of NTS ${ }^{\mathrm{CeA}}$ neurons decreases ethanol consumption in two-bottle choice

To determine whether NTS ${ }^{\mathrm{CeA}}$ neurons play a role in ethanolrelated behavior, we used NTS-IRES-Cre-recombinase (NTSCre) mice (Leinninger et al., 2011) in conjunction with viral manipulations in the CeA. First, we validated the fidelity and penetrance of Cre in the CeA of this line. Using FISH (Fig. 2A), we double-labeled Nts and Cre mRNA in CeA slices from five separate NTS-Cre mice. We found that $61.4 \%$ of Nts mRNAexpressing cells also expressed Cre and we found that $82.2 \%$ of Cre mRNA-expressing cells also expressed Nts mRNA. These data indicate this is a high-fidelity Cre line with strong penetrance.

We next injected a Cre-dependent virus encoding a modified pro-caspase 3 and TEV protease (AAV5-Ef1a-FLEX-taCaspTEVp; Yang et al., 2013) into the CeA of NTS-Cre mice to selectively lesion $N T S^{\mathrm{CeA}}$ neurons (NTS ${ }^{\mathrm{CeA}}:$ :casp; Fig. 2B). This
}

strategy resulted in a $51.7 \%$ reduction in NTS-positive cells in the CeA (Fig. 2C) and a 40.9\% reduction in CeA-NTS immunoreactivity, without altering NTS-ir in the neighboring LH (Fig. 2D). Control animals were injected with a Cre-dependent eYFP construct (NTS ${ }^{\mathrm{CeA}}:$ :eYFP).

Because of the importance of the CeA in ethanol consumption (Gilpin et al., 2015), we hypothesized the loss of NTS ${ }^{\mathrm{CeA}}$ neurons would alter voluntary ethanol consumption in a continuous twobottle choice paradigm. NTS ${ }^{\mathrm{CeA}}$ ::casp mice showed significant decreases in ethanol consumed in $24 \mathrm{~h}$ two-bottle choice drinking compared with $N T S^{\mathrm{CeA}}:$ :eYFP controls (Fig. 3A; two-way ANOVA: interaction: $F_{(2,42)}=6.340, p=0.0039$; ethanol concentration: $F_{(2,42)}=98.23, p<0.0001$; ablation: $F_{(1,21)}=16.52$, $p=0.0006)$, with no effect of preference for the ethanol bottle (Fig. 3B; two-way ANOVA: interaction: $F_{(2,42)}=1.793, p=$ 0.1790 ; ethanol concentration: $F_{(2,42)}=7.727, p=0.0014$; ablation: $\left.F_{(1,21)}=3.283, p=0.0843\right)$. NTS ${ }^{\mathrm{CeA}}$ ::casp animals also showed decreased liquid consumption at lower ethanol concentrations, which was driven by increased total drinking by the $N T S^{\mathrm{Ce}}$ ::eYFP mice at lower ethanol concentrations (Fig. 3F; two-way ANOVA: interaction: $F_{(2,42)}=6.551, p=0.0033$; ethanol concentration: $F_{(2,42)}=47.02, p<0.0001$; ablation: $F_{(1,21)}=$ $9.208, p=0.0063)$. Because of this, we next determined whether NTS ${ }^{\mathrm{CeA}}$ ::casp mice showed general differences in liquid consumption compared with controls and measured water drinking over $5 \mathrm{~d}$. NTS ${ }^{\mathrm{CeA}}$ ::casp mice drank the same amount of water as NTS ${ }^{\mathrm{CeA}}:: \mathrm{eYFP}$ mice (Fig. 3G; two-way ANOVA: interaction: $F_{(4,44)}=2.459, p=0.0593$; ablation: $F_{(1,11)}=1.005, p=0.3377$; day: $\left.F_{(4,44)}=2.714, p=0.0418\right)$, confirming that NTS ${ }^{\mathrm{CeA}}$ ablation affects ethanol consumption as opposed to general liquid consumption.

To determine whether this decrease in alcohol consumption was due to an increase in aversion to a bitter tastant, or decreased hedonic value for a rewarding fluid, we performed a series of two-bottle choice preference tests with multiple caloric and noncaloric tastants. In a new cohort of animals, the NTS ${ }^{\mathrm{CeA}}:$ :eYFP and NTS ${ }^{\mathrm{CeA}}:$ :casp groups showed no difference in preference for 
sucrose (Fig. 3C; two-way ANOVA: interaction: $F_{(4,44)}=0.8346, p=0.5106$; concentration: $F_{(4,44)}=76.89, p<0.0001$; ablation: $\left.F_{(1,11)}=0.8047, p=0.3889\right)$, saccharin (Fig. $3 D$; two-way ANOVA: interaction: $F_{(3,33)}=0.4399, p=0.7260$; concentration: $F_{(3,33)}=134.0, p<0.0001$; ablation: $\left.F_{(1,11)}=1.063, p=0.3246\right)$ or quinine (Fig. $3 E$; two-way ANOVA: interaction: $F_{(5,55)}=1.139, p=0.3511$; concentration: $F_{(5,55)}=52.53, p<0.0001$; ablation: $\left.F_{(1,11)}=0.6999, p=0.4206\right)$. Additionally, the NTS ${ }^{\text {eA }}:$ :eYFP and $N T S^{\mathrm{CeA}}$ ::casp groups did not differ in the consumed volume (liquid $\mathrm{g} / \mathrm{kg}$ ) of any of these tastants (sucrose two-way ANOVA: interaction: $F_{(4,44)}=0.4449, p=0.7755$; sucrose concentration: $F_{(4,44)}=109.1$, $p<0.0001$; ablation: $F_{(1,11)}=0.2132, p=$ $0.6533)$; saccharin two-way ANOVA: interaction: $F_{(3,33)}=0.2004, p=0.8954$; saccharin concentration: $F_{(3,33)}=126.2$, $p<0.0001$; ablation: $F_{(1,11)}=8.016, p=$ $0.3781)$; quinine two-way ANOVA: interaction: $F_{(5,55)}=0.7687, p=0.5764$; quinine concentration: $F_{(5,55)}=52.51, p<$ 0.0001; ablation: $F_{(1,11)}=1.254, p=$ $0.2866)$. Last, the daily total liquid consumed was not different between the $N T S^{\mathrm{CeA}}:: \mathrm{eYFP}$ and $N T S^{\mathrm{CeA}}$ ::casp groups for either sucrose (Fig. $3 H$; two-way ANOVA: interaction: $F_{(4,44)}=0.4976$, $p=0.7375$; concentration: $F_{(4,44)}=69.17$, $p<0.0001$; ablation: $F_{(1,11)}=0.2049, p=$ 0.6596), saccharin (Fig. 3I; two-way ANOVA: interaction: $F_{(3,33)}=0.2906$, $p=0.8318$; concentration: $F_{(3,33)}=86.01$, $p<0.0001$; ablation: $F_{(1,11)}=0.5694, p=$ 0.4664 ) or quinine (Fig. 3J; two-way ANOVA: interaction: $F_{(5,55)}=1.092, p=$ 0.3754; concentration: $F_{(5,55)}=2.456, p=$ 0.0444; ablation: $F_{(1,11)}=0.2943, p=$ $0.5983)$. These data suggest that the decrease in ethanol intake measured in $N T S^{\mathrm{CeA}}:$ :casp animals was not due to changes in general fluid intake, motivation to drink rewarding fluids in general, or aversion to bitter tastants, but was instead specific for ethanol.

We wanted to verify that genetic ablation of NTS ${ }^{\mathrm{CeA}}$ neurons did not result in gross changes in body weight or movement. We measured body weight for a month following stereotactic surgery and found that this lesion did not alter body weight (Fig. 4A; two-way ANOVA: interaction: $F_{(26,208)}=0.9646$; day: $F_{(26,208)}=$ 40.11, $p<0.0001, p=0.5180$; ablation: $\left.F_{(1,8)}=0.1154, p=0.7428\right)$. We also tested the animals in an open field and found no changes in locomotor behavior measured as either distance traveled (Fig. 4B; two-way ANOVA, interaction: $F_{(2,36)}=0.9989, p=0.3783$; time: $F_{(2,36)}=$ $109.3, p<0.0001$; ablation: $\left.F_{(1,18)}=0.1886, p=0.6693\right)$ or velocity basolateral amygdala.
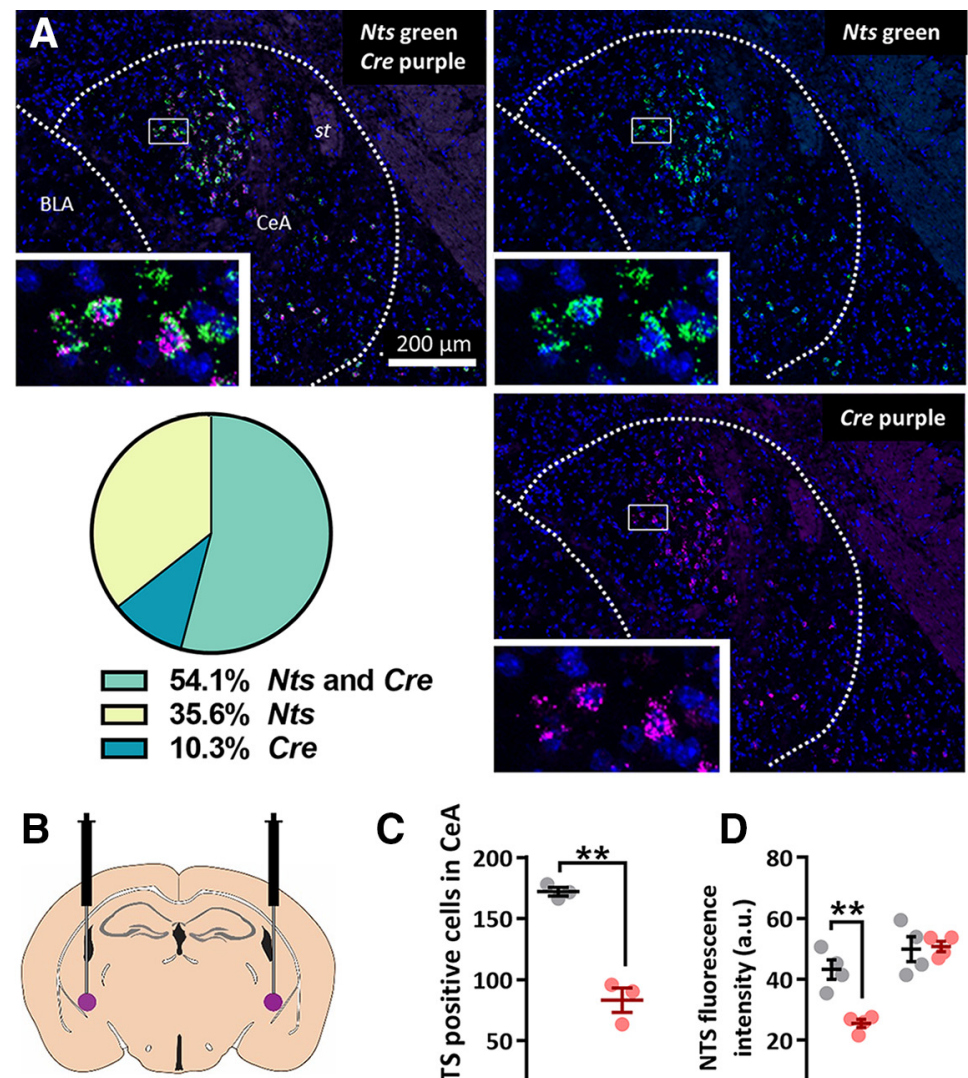

AAV-syn-flex-taCasp3-TEVp
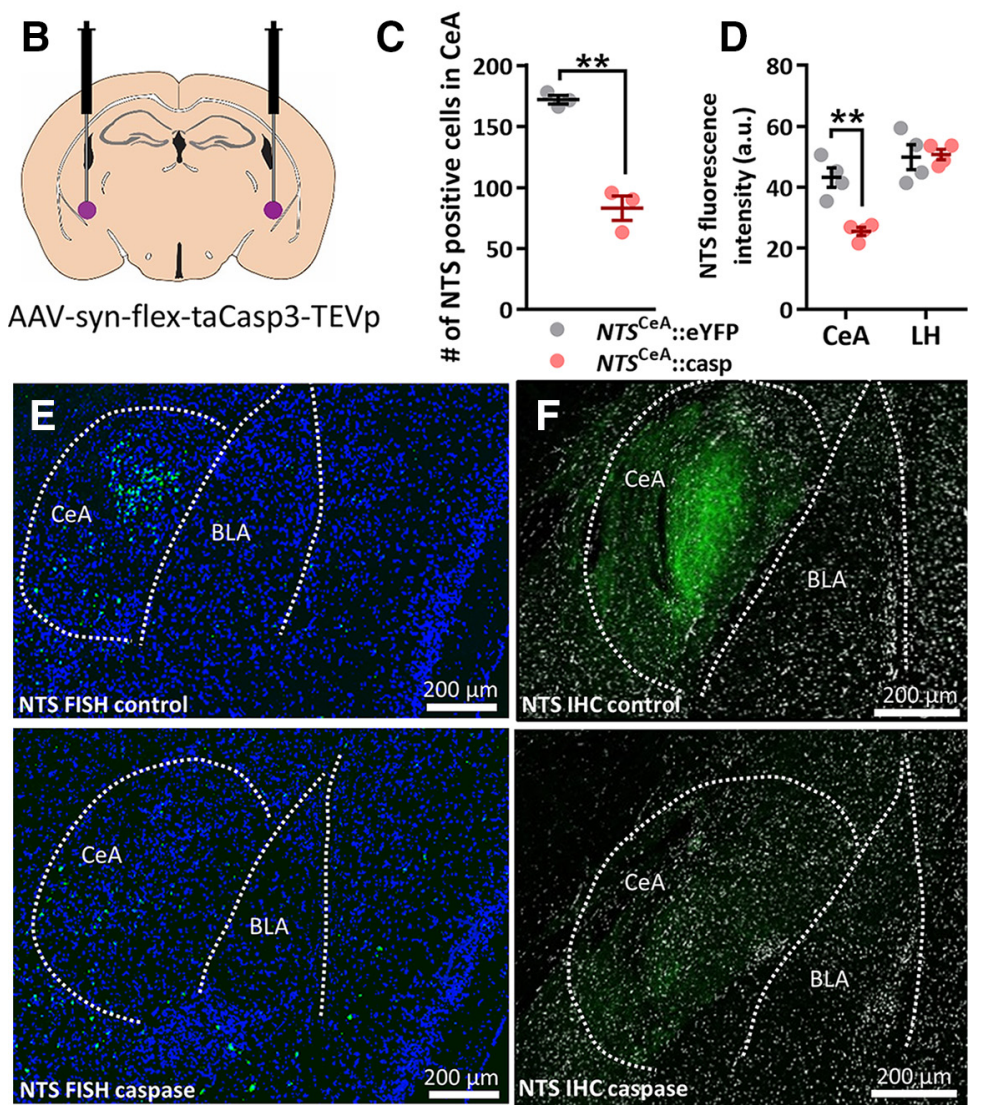

Figure 2. NTS-Cre line and caspase manipulation validation. $A$, Dual FISH of Nts (green) and (re (purple) in the CeA with DAPI (blue). Nts mRNA-expressing cells (61.4\%; $241.2 \pm 29.7 \mathrm{Nts}+$ cells per slice) also expressed Cre (145.4 $\pm 23.7 \mathrm{Nts}+$ Cre + cells per slice) and $82.2 \%$ of (re mRNA-expressing cells ( $173.2 \pm 22.8$ Cre + cells per slice) also expressed Nts mRNA ( $n=3$ mice, $5-6$ slices/mouse). B, Diagram of CeA injection site. C, Quantification of cells FISH labeled for Nts in the CeA from NTS ${ }^{\text {CeA.:. }}$.asp $(n=3)$ and NTS CeA.:.eYFP animals $\left(n=3\right.$; unpaired $t$ test: $\left.t_{(4)}=8.425, p=0.0011\right)$. $\boldsymbol{D}$, Caspase ablation decreased NTS immunoreactivity as measured in arbitrary units (a.u.) in the CeA (unpaired $t$ test: $\left.t_{(6)}=5.090, p=0.0022\right)$, but not in the LH (unpaired $t$ test: $t_{(6)}=$ $0.1956, p=0.8514)$. Representative images of in situ $(\boldsymbol{E})$ and IHC $(\boldsymbol{F}) .{ }^{* *} p<0.01$ unpaired $t$ test. st, Stria terminalis; BLA,

(Fig. 4C; two-way ANOVA, interaction: $F_{(2,38)}=0.9970, p=0.3784$; time: $F_{(2,38)}=98.55, p<0.0001$; ablation: $F_{(1,19)}=0.2698, p=$ $0.6095)$. We next wanted to verify that $N T S^{\mathrm{CeA}}$ ::casp animals did not have differences in other ethanol-related traits that might be respon- 
A

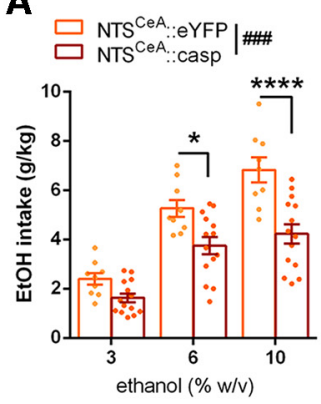

F

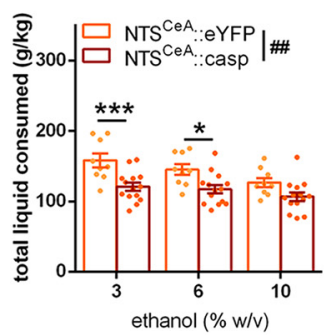

B

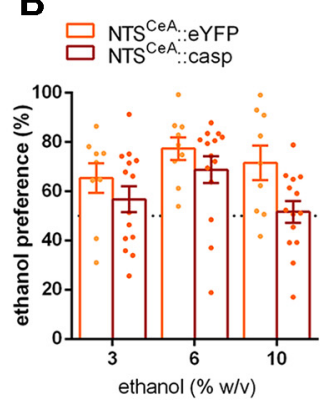

G

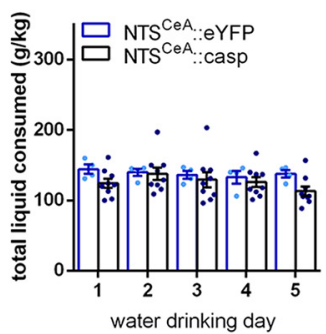

C

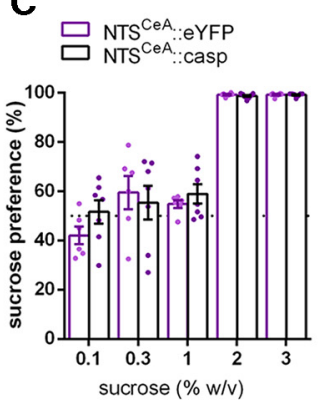

H

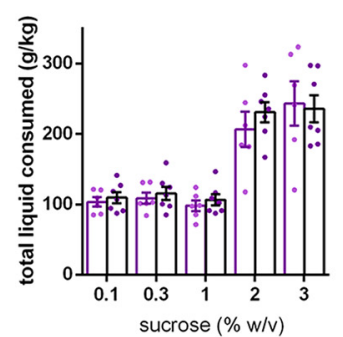

D

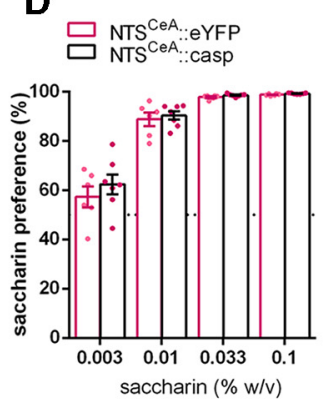

I

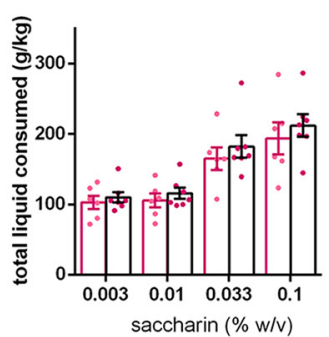

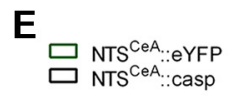

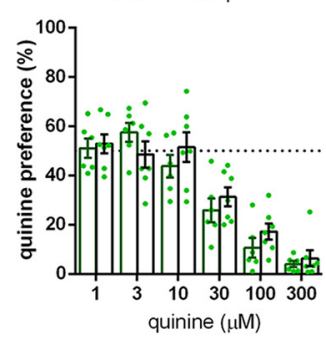

J

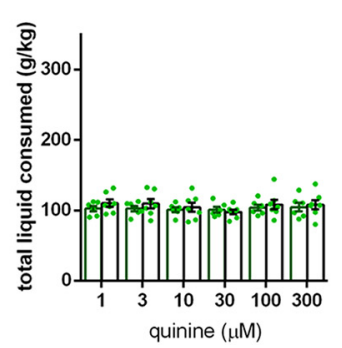

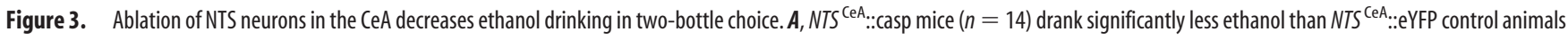
$(n=9)$. $\boldsymbol{B}$, Preference for the tastant bottle was not significantly different between these groups for either ethanol, (C) sucrose (eYFP $n=6, \operatorname{casp} n=7)$, (D) saccharin (eYFP $n=6$, casp $n=7$ )

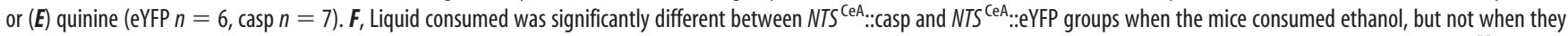
consumed $(\boldsymbol{G})$ water (eYFP $n=4$, casp $n=9)$, $(\boldsymbol{H})$ sucrose, $(\boldsymbol{I})$ saccharin, or $(\boldsymbol{J})$ quinine. Bonferroni-corrected $t$ tests: ${ }^{*} p<0.05,{ }^{* * *} p<0.001,{ }^{* * * *} p<0.0001$; ANOVA main effects: ${ }^{* \#} p<0.01$ $\# \#$ \# $<0.001$.

A
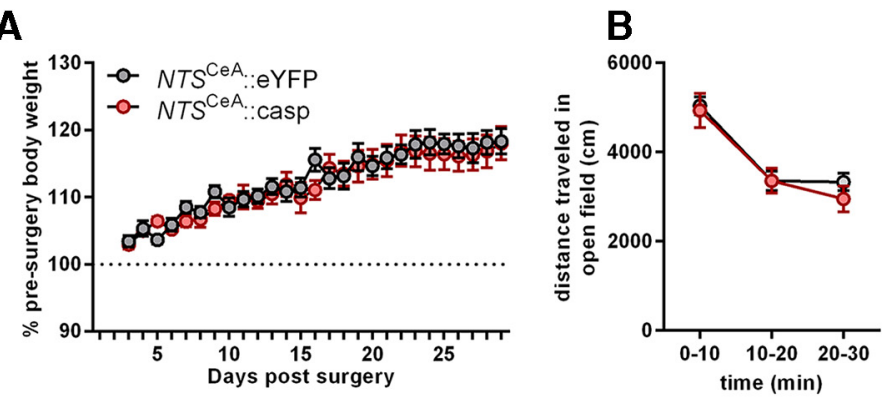

$\mathbf{F}$

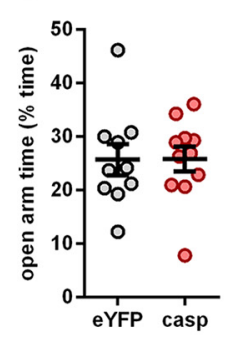

G

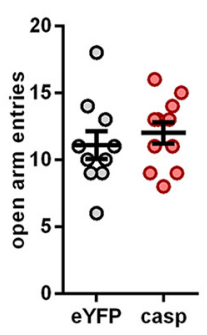

H

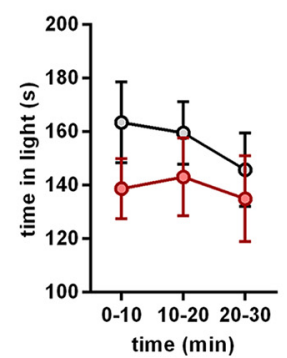

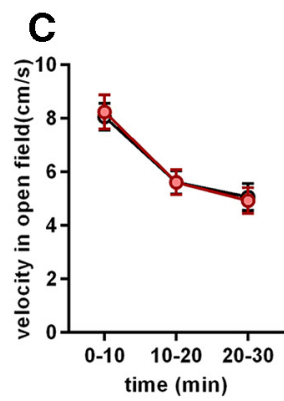

J

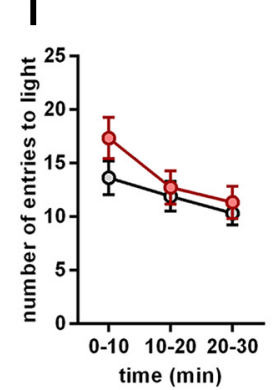

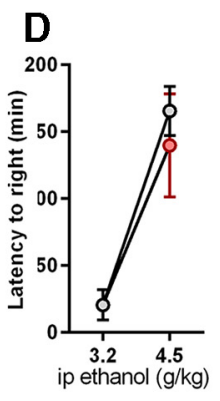

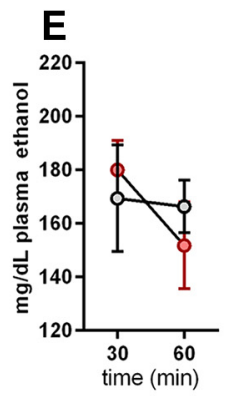

$\mathrm{K}$

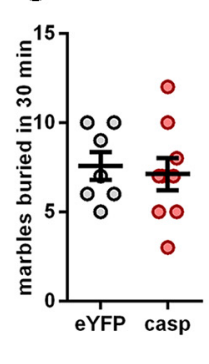

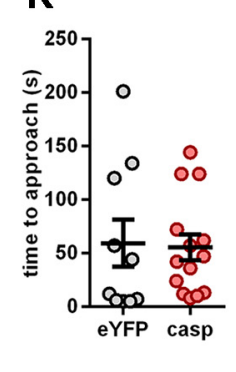

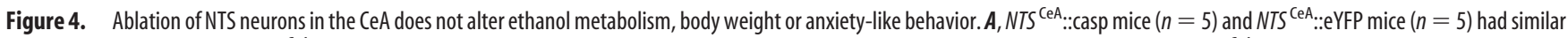
growth curves postsurgery. $\boldsymbol{B}$, NTS $^{\mathrm{CeA}}$ ablation did not affect either distance traveled or (C) velocity in an open field (eYFP $n=9$, casp $n=11$ ). D, NTS ${ }^{\text {CeA }}$ ablation did not affect latency to right following a $3.2 \mathrm{~g} / \mathrm{kg}$ or $4.5 \mathrm{~g} / \mathrm{kg}$ ethanol intraperitoneal injection (eYFP $n=6$, casp $n=7$ ). $\boldsymbol{E}$, Blood alcohol concentrations following administration of $2.0 \mathrm{~g} / \mathrm{kg}$ (i.p.) ethanol was not affected by NTS ${ }^{\text {CeA }}$ ablation (eYFP $n=5$, casp $n=5$ ). $\boldsymbol{F}$, NTS ${ }^{\text {CeA }}$ ablation did not affect either time spent in or (G) entries to the open arms of an elevated plus maze (eYFP $n=10$, casp $n=11$ ). $\boldsymbol{H}$, NTS ${ }^{\text {CeA }}$

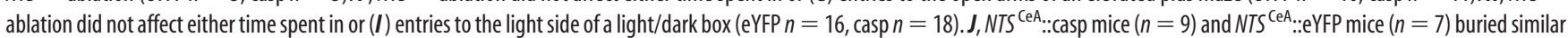

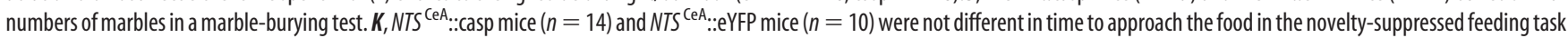
or in $(\boldsymbol{L})$ the 10 min consumption post-test.

sible for their blunted drinking, specifically sedation following a high dose of ethanol and ethanol metabolism. NTS ${ }^{\mathrm{CeA}}$ neuron ablation did not change sedation in response to ethanol (Fig. $4 D ; 3.2 \mathrm{~g} / \mathrm{kg}$ dose, unpaired $t$ test: $t_{(10)}=0.0001, p=0.9999 ; 4.5 \mathrm{~g} / \mathrm{kg}$ dose, unpaired $t$ test: $\left.t_{(11)}=0.5696, p=0.5804\right)$ or ethanol metabolism as measured by BEC following intraperitoneal injection of $2.0 \mathrm{~g} / \mathrm{kg}$ of ethanol (Fig. 4E; twoway ANOVA, interaction: $F_{(1,8)}=1.270, p=0.2924$; time: $F_{(1,8)}=$ $1.964, p=0.1987$; ablation: $\left.F_{(8,8)}=2.538, p=0.1046\right)$. 
Ablation of NTS ${ }^{\mathrm{CeA}}$ neurons does not impact anxiety-like behavior Given the potential role of the CeA in anxiety, we also conducted a series of behavioral tests to measure anxiety-like responses. Genetic ablation failed to alter anxiety-like behaviors as measured by: time spent in and entries to the open arms of an elevated plus maze (Fig. $4 F, G$; time spent, unpaired $t$ test: $t_{(19)}=0.03167, p=$ 0.9751 ; entries, unpaired $t$ test: $t_{(19)}=$ 0.6992, $p=0.4929$ ), time spent in and entries to the light side of a light/dark box (Fig. 4H, I; time spent, two-way ANOVA, interaction: $F_{(2,64)}=0.3707, p=0.6917$; time: $F_{(2,64)}=1.203, p=0.3071$; ablation: $F_{(1,32)}=1.000, p=0.3247$; entries, twoway ANOVA, interaction: $F_{(2,60)}=1.452$, $p=0.2422$; time: $F_{(2,60)}=14.63, p<$ 0.0001 ; ablation: $F_{(1,30)}=0.7529, p=$ 0.3924), marble-burying (Fig. 4J; unpaired $t$ test: $\left.t_{(14)}=0.3716, p=0.7158\right)$, or novelty-suppression of feeding (Fig. $4 K, L$; unpaired $t$ test: $t_{(22)}=0.1597, p=$ $0.8746)$. Based on these data, genetic ablation of $N T S^{\mathrm{CeA}}$ neurons selectively reduced alcohol consumption without affecting motor function, the sedativehypnotic effects of ethanol, blood ethanol clearance, or anxiety-like behavior.

\section{Ablation of NTS ${ }^{\mathrm{CeA}}$ neurons decreases ethanol consumption in intermittent access}

Because of the ethanol dose effect observed with our initial two-bottle choice experiments (Fig. 3A), we next examined whether ablation of NTS ${ }^{\mathrm{CeA}}$ neurons would alter ethanol consumption in a drinking paradigm with a longer schedule of access and a higher dose of alcohol. We used an IA drinking paradigm in an attempt to increase alcohol consumption. $N T S^{\mathrm{CeA}}:$ :casp mice again showed significant decreases in ethanol consumed across all weeks compared with NTS ${ }^{\mathrm{CeA}}:$ : eYFP controls (Fig. 5A; two-way ANOVA, interaction: $F_{(6,126)}=0.4321, p=0.8564$; week: $F_{(6,126)}=2.539$, $p=0.0235$; ablation: $\left.F_{(1,21)}=11.19, p=0.0031\right)$ as well as cumulative ethanol consumption (Fig. $5 B$; two-way ANOVA, interaction: $F_{(20,380)}=13.53, p<0.0001$; day: $F_{(20,380)}=194.5, p<$ 0.0001 ; ablation: $F_{(1,19)}=11.69, p=0.0029$; Bonferronicorrected post hoc tests show significant difference between $N T S^{\mathrm{CeA}}::$ casp and $N T S^{\mathrm{CeA}}:: \mathrm{eYFP}$ at Days 26-47). Total liquid consumed was unaffected whether measured by week (Fig. $5 C$; two-way ANOVA, interaction: $F_{(6,126)}=1.525, p=0.1752$; week: $F_{(6,126)}=8.358, p<0.0001$; ablation: $F_{(1,21)}=0.00005215, p=$ 0.9943 ) or cumulative intake (Fig. $5 D$; two-way ANOVA, interaction: $F_{(20,420)}=0.1298, p>0.9999$; day: $F_{(20,420)}=861.7, p<$ 0.0001 ; ablation: $\left.F_{(1,21)}=0.01703, p=0.8976\right)$. NTS ${ }^{\text {CeA }}:$ :casp mice also showed a significant decrease in preference for the ethanol bottle (Fig. 5E; two-way ANOVA, interaction: $F_{(6,126)}=$ $0.7778, p=0.588$; week: $F_{(6,126)}=3.992, p=0.0011$; ablation:
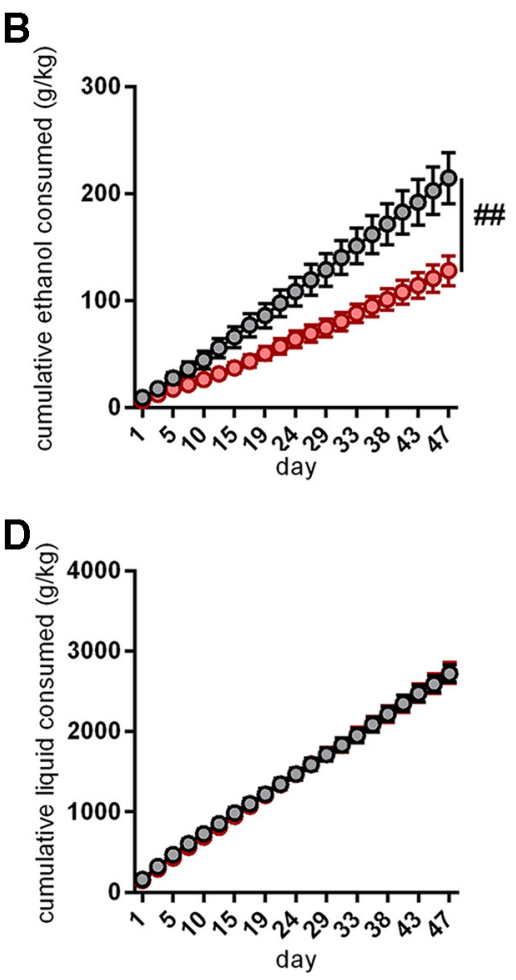

$\mathbf{F}$

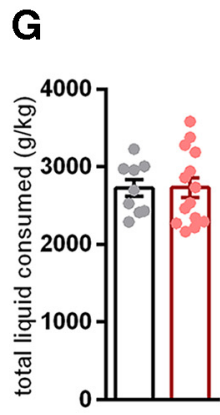

Figure 5. Ablation of NTS neurons in the CeA decreases ethanol drinking and preference in an IA paradigm. $A$, NTS ${ }^{\text {CeA.:.: }}$ :asp mice $(n=14)$ consume less ethanol than NTS ${ }^{\mathrm{CeA}}:$ :eYFP mice $(n=9)$ in an IA paradigm whether measured weekly or $(\boldsymbol{B})$ cumulatively. , experiment (each circle represents an ethanol drinking day). $E$, Preference for the ethano

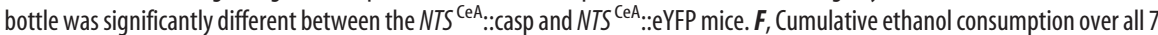

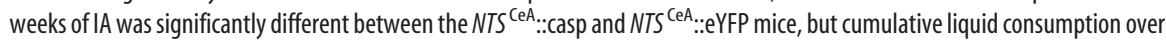
the same period was not (G). Unpaired $t$ tests: ${ }^{* *} p<0.01$; ANOVA main effects: ${ }^{\# \#} p<0.01$, ${ }^{\# \#} p<0.001$.

$\left.F_{(1,21)}=15.88, p=0.0007\right)$. Last, we compared the total amount consumed at the end of the 7 weeks of IA. NTS ${ }^{\text {CeA }:: \text { casp mice }}$ consumed significantly less total ethanol than NTS ${ }^{\mathrm{CeA}}:$ :eYFP mice (Fig. $5 F$; unpaired $t$ test: $t_{(21)}=3.413, p=0.0026$ ), with no detectable difference in total liquid consumed (Fig. $5 G$; unpaired $t$ test: $\left.t_{(21)}=0.04085, p=0.9678\right)$. These experiments suggest that NTS ${ }^{\mathrm{CeA}}$ neurons regulate ethanol consumption across multiple dose ranges and schedules of access.

\section{Neurons in the central amygdala are activated by} various tastants

To determine whether Nts neurons in the CeA would be activated following voluntary consumption of ethanol, we performed dual FISH for Nts and Fos in CeA slices. Singly-housed male C57BL/6J mice were allowed access to either water, $6 \%$ ethanol, $1 \%$ sucrose, $0.03 \%$ saccharin, or $100 \mu \mathrm{M}$ quinine and for $2 \mathrm{~h}$ during 4 consec- 

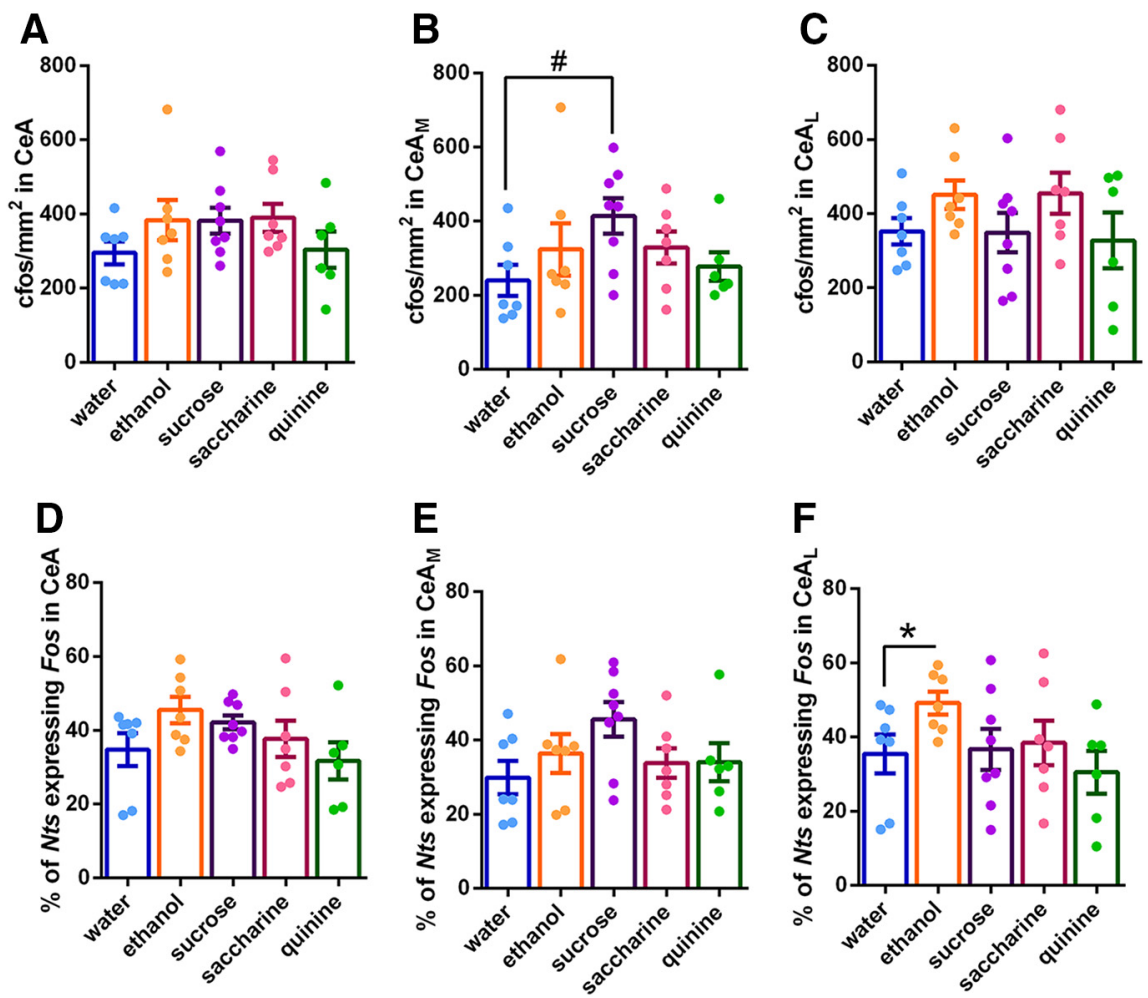

Figure 6. Nts + neurons in the lateral CeA are activated by ethanol in vivo. C57BL/6J mice consumed either water $(n=7), 6 \%$ ethanol $(n=7), 1 \%$ sucrose $(n=8), 0.03 \%$ saccharin $(n=7)$, or $100 \mu \mathrm{m}$ quinine $(n=6)$. $A$, Fos expression in the CeA $_{\text {total }}$ as a whole was unchanged across all tastants. $\boldsymbol{B}$, Sucrose consumption increased Fos expression in the CeA $A_{M}$ but not in $(\boldsymbol{C})$ the CeA $A_{L}$. D , The percentage of Nts neurons expressing Fos was unchanged by tastant exposure in the $\mathrm{CeA}_{\text {total }}$ and $(\boldsymbol{E}) \mathrm{CeA}_{\mathrm{M}}$. $\boldsymbol{F}$, Ethanol consumption increased Fos expression in Nts neurons in the CeA. Planned unpaired $t$ test: ${ }^{*} p<0.05$; Dunnett's multiplecomparisons test: $\# p<0.01$.

utive days. On the fifth day, the mice consumed fluid for $1 \mathrm{~h}$ and were killed $30 \mathrm{~min}$ later for FISH. The average fluid consumption for these groups was $8.34 \mathrm{~g} / \mathrm{kg}(4.49 \mathrm{SD})$ for water, $10.44 \mathrm{~g} / \mathrm{kg}$ (6.18 SD) for ethanol, $32.84 \mathrm{~g} / \mathrm{kg}(15.96 \mathrm{SD})$ for sucrose, 36.25 $\mathrm{g} / \mathrm{kg}(8.86 \mathrm{SD})$ for saccharin, and $5.34 \mathrm{~g} / \mathrm{kg}$ (3.94 SD) for quinine. This home-cage drinking failed to induce changes in Fos mRNA expression in the CeA when analyzed in total (Fig. 6A), however, work investigating genetically-defined subpopulations of neurons in the CeA suggests that Nts neurons can be subdivided into functionally separate medial $\left(\mathrm{CeA}_{\mathrm{M}}\right)$ and lateral $\left(\mathrm{CeA}_{\mathrm{L}}\right)$ populations (Kim et al., 2017). We thus subdivided the images into $\mathrm{CeA}_{\mathrm{M}}$ and $\mathrm{CeA}_{\mathrm{L}}$, focusing on slices located from -1.1 to -1.8 posterior to bregma, where it was easier to delineate between these two regions. Tastant consumption did not change Fos expression compared with the water group (Fig. 6B,C), with the exception of sucrose consumption increasing Fos specifically in the $\mathrm{CeA}_{\mathrm{M}}$ (Fig. 6B; Dunnett's multiple-comparisons test: water vs sucrose, adjusted $p=0.0367)$. We then examined activation of Nts neurons specifically (Fig. $6 D-F$ ). We performed an a priori planned comparison between the water and ethanol groups as the $N T S^{\mathrm{CeA}}$ ::casp animals only showed a phenotype for ethanol drinking. Interestingly, ethanol consumption resulted in an increase in the percentage of Fos-expressing Nts neurons in the $\mathrm{CeA}_{\mathrm{L}}$ (Fig. $6 F$; unpaired $t$ test with Welch's correction: $t_{(9.685)}=$ $2.248, p=0.0491)$. These data suggest that the $\mathrm{CeA}_{\mathrm{L}}$ group of NTS neurons might be responsible for the ethanol phenotype seen in the NTS ${ }^{\mathrm{CeA}}$ ::casp animals.

\section{$N T S^{\mathrm{CeA}}$ neurons send a dense projection to the $\mathrm{PBN}$}

To begin to examine the targets of NTS $\mathrm{CeA}$ neurons, we injected a Cre-dependent virus expressing channelrhodopsin-2 tagged with eYFP (ChR2-eYFP) into the CeA of NTS-IRES-Cre mice (Fig. $7 A, B$ ). Using whole-cell ex vivo slice electrophysiology and recording in current clamp, we found that $473 \mathrm{~nm}$ light stimulation (20 $\mathrm{Hz}, 5 \mathrm{~ms}$ pulse) readily evoked action potentials in NTS ${ }^{\mathrm{CeA}}:$ :ChR2 neurons (data not shown). We observed a projection from NTS ${ }^{\mathrm{CeA}}$ neurons to the hindbrain near the fourth ventricle with robust fluorescence expression in the PBN and the lateral edge of the locus ceruleus (LC; Fig. $7 C$ ), as well as a projection to the bed nucleus of the stria terminalis (BNST), which was particularly dense in the ventral fusiform subnucleus (Fig. 7D). We found significantly greater fluorescence expression in the PBN versus the LC (Fig. $7 E$; unpaired $t$ test: $t_{(6)}=14.59, p<$ $0.0001)$. However, LC neurons extend long dendritic processes into the boundaries of the PBN (Swanson, 1976) so we next sought to determine where NTS ${ }^{\mathrm{CeA}}$ neurons make functional synaptic connections using electrophysiology.

Monosynaptic input was isolated in whole-cell patch-clamp recordings with TTX (500 $\mu \mathrm{M})$ and 4-AP (1 mM). $473 \mathrm{~nm}$ light stimulation ( $5 \mathrm{~ms}$ ) of CeA-NTS terminals induced an optically-evoked inhibitory postsynaptic current (oeIPSC) in both the medial and lateral PBN which was blocked by the GABAA receptor antagonist gabazine (10 $\mu \mathrm{M}$; Fig. $7 F$, example trace), whereas no inhibitory or excitatory synaptic currents were observed in the LC (Fig. $7 G)$. These data suggest that the NTS ${ }^{\mathrm{CeA}}$ neurons make functional inhibitory synaptic connections in the lateral and medial portions of the PBN ( 8 of 10 cells, and 9 of 10 cells, respectively) but not the LC ( 0 of 10 cells, $n=6$ mice). Although we do not know the genetic identity of the PBN neurons receiving this innervation, the possibility remains that these neurons may reciprocally project to the CeA as both Oxtr ${ }^{\mathrm{PBN}}$ and $\mathrm{Calca}^{\mathrm{PBN}}$ neurons regulate fluid intake (Carter et al., 2013; Ryan et al., 2017).

We also verified a synaptic inhibitory $N T S^{\mathrm{CeA}}$ projection to the BNST, which was stronger in the ventral portion ( 9 of 10 cells) than in the dorsal portion ( 6 of 10 cells). We also found strong local connections within the CeA. All non-eYFP labeled cells examined ( 11 of 11 cells, $n=4$ mice) exhibited an optically evoked IPSC. Interestingly, three of these eYFP- cells were BNSTprojecting neurons identified using retrobeads injected into the BNST. This strong local inhibition from NTS ${ }^{\mathrm{Ce}}$ neurons, in conjunction with our Fos FISH tastant study (see previous section), suggested that cell-body optogenetic stimulation of the entire NTS ${ }^{\mathrm{CeA}}$ population might not be reflective of the activation of these neurons in vivo, thus, we decided to pursue a pathway-specific strategy.

To narrow our focus of target regions, we explored the two nuclei where we observed the densest fiber innervation following 


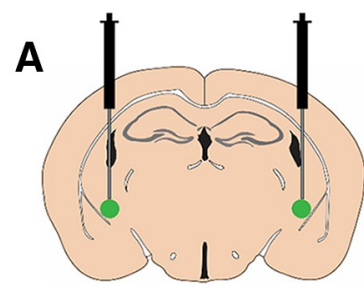

AAV-Ef1a-DIO-ChR2-eYFP

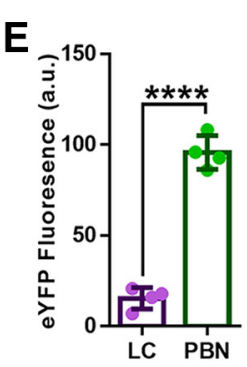

$\mathbf{F}$
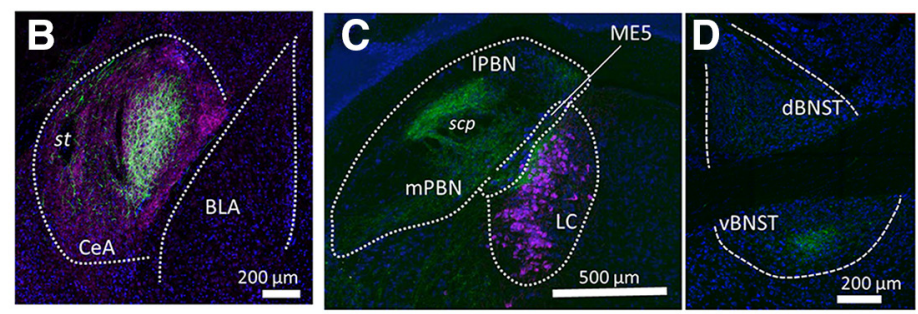

G
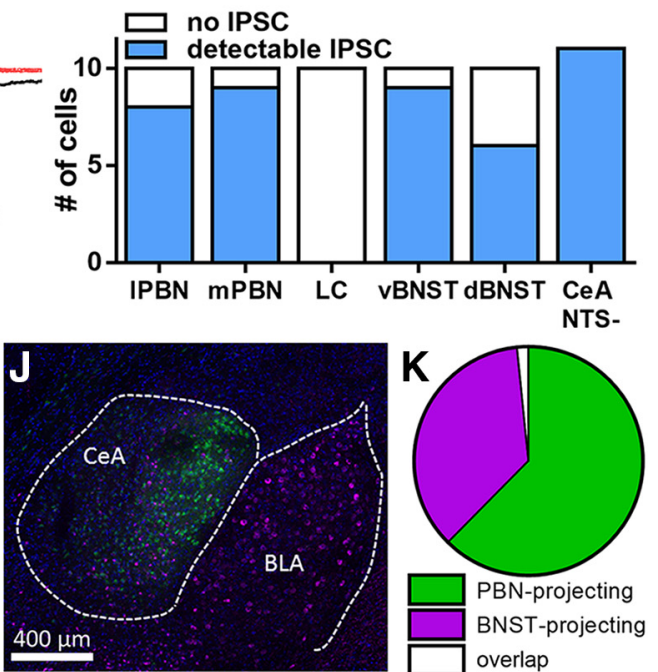

Figure 7. NTS ${ }^{\text {CeA }}$ neurons project to the PBN. A, Diagram of injection site in the CeA of AAV-EF1 $\alpha$-DIO-ChR2-eYFP in the CeA of NTS-IRES-Cre mice. $B$, Representative image of CeA expression of ChR2-eYFP

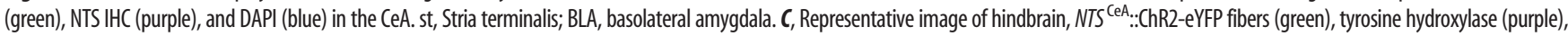

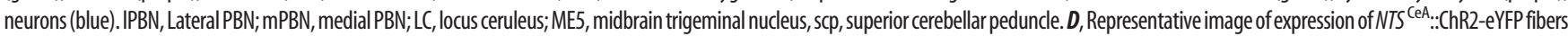
(green) in the BNST with DAPI staining (blue). dBNST, Dorsal portion of the BNST; vBNST, ventral portion of the BNST. E, PBN has significantly greater eYFP fluorescence intensity (a.u.) compared with the LC in

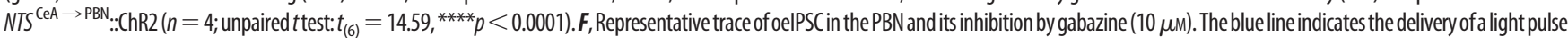
(5 ms). G, Quantification of cells with light-evoked responses in NTS ${ }^{\text {CeA }}$ animals in the IPBN (8/10 cells), mPBN (9/10 cells), LC (0/10 cells), vBNST (9/10 cells), dBNST (6/10 cells), as well as eYFP- CeA neurons (11/11). H, Representative BNST image of retrograde (TXb tracing experiment (ov, oval nucleus of the BNST; fu, fusiform nucleus of the BNST).I, Representative PBN image of retrograde CTXb tracing experiment. $\boldsymbol{J}$, RepresentativeCeA image of retrograde CTXb tracing experiment. Green, Cells projecting to the PBN; purple, cells projecting to the BNST. $K$, Quantification of cell body fluorescence expression (green and purple (TXb) in the CeA ( $n=3$ mice). $62.4 \%$ of labeled neurons projected to the PBN, $36.0 \%$ projected to the BNST, and $1.6 \%$ of cells were doubly-labeled.

the expression of ChR2 in the NTS ${ }^{\mathrm{CeA}}$ the BNST and PBN. To determine whether individual $N T S^{\mathrm{CeA}}$ neurons collateralize to both the BNST and PBN, we injected the retrograde tracer Alexa555 cholera toxin-b (CTXb) into the BNST (Fig. 7H) and AlexaFluor 488 (CTXb into the PBN) Fig. 7I of the same animal. We found minimal overlap between BNST- and PBN-projecting neurons (1.6\%; Fig. $7 \mathrm{~J}, K)$ suggesting that these are distinct cell populations within the CeA. Somewhat surprisingly, we also noted that the BNST- and PBN-projecting neurons in the CeA appear to have a medial-lateral gradient, with the larger population of PBN-projecting neurons located in the $\mathrm{CeA}_{\mathrm{L}}$. Combining this observation with the significant elevation of Fos in the $\mathrm{CeA}_{\mathrm{L}}$ following moderate ethanol consumption, the established role for the PBN in consummatory behaviors, we hypothesized that the CeA-NTS projection to the PBN could potentially have a role in alcohol consumption.

\section{$N T S^{\mathrm{CeA}}$ projection to the $\mathrm{PBN}$ is reinforcing}

Before investigating the role of the NTS ${ }^{\mathrm{CeA} \rightarrow \mathrm{PBN}}$ on consummatory behavior, we assayed the behavioral effects of pathway stimulation on measures of anxiety-like behavior and appetitive/ aversive behavior. Consistent with the lack of effect on anxietylike behavior noted with $N T S^{\mathrm{CeA}}::$ casp mice, $20 \mathrm{~Hz}$ optical

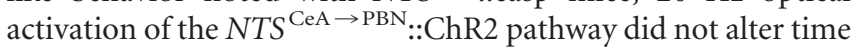

spent in the center of an open field (Fig. $8 \mathrm{~A}$; unpaired $t$ test: $t_{(7)}=$ $1.163, p=0.2830$ ). Stimulation of the NTS ${ }^{\mathrm{CeA} \rightarrow \mathrm{PBN}}$ projection also failed to impact behavior in the elevated plus maze either in open arm entries (Fig. $8 B$; two-way ANOVA, interaction: $F_{(2,27)}=$ $0.01082, p=0.9892$; stimulation: $F_{(2,27)}=0.1085, p=0.8976$; virus type: $\left.F_{(1,27)}=0.4477, p=0.5091\right)$ or in time spent in the open arm (Fig. $8 C$; interaction: $F_{(2,27)}=0.6265, p=0.5421$; stimulation: $F_{(2,27)}=3.034, p=0.0648$; virus type: $F_{(1,27)}=$ $0.6867, p=0.4146)$, indicating that activating this pathway in naive mice does not alter anxiety-like behaviors.

To probe whether stimulation of the NTS ${ }^{\mathrm{CeA} \rightarrow \mathrm{PBN}}$ pathway altered affective valence, we examined response to photostimulation in the RTPP assay. Photostimulation of these fibers at 20 $\mathrm{Hz}$ induced a significant RTPP in $N T S^{\mathrm{CeA} \rightarrow \mathrm{PBN}:: \mathrm{ChR} 2-\mathrm{eYFP}}$

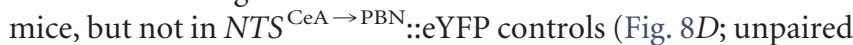
$t$ test: $\left.t_{(25)}=6.128, p<0.0001\right)$ suggesting that these neurons convey positive valence. We also wanted to confirm whether time spent in the stimulation side was significantly different from chance and found that this was the case for NTS ${ }^{\mathrm{CeA} \rightarrow \mathrm{PBN}}:: \mathrm{ChR} 2-$ eYFP mice (one-sample $t$ test, control: $t_{(12)}=0.2835, p=0.7817$, ChR2-eYFP: $\left.t_{(13)}=8.183, p<0.0001\right)$. To inhibit the terminals of NTS ${ }^{\mathrm{CeA}}$ neurons in the PBN we expressed the blue light activated chloride channel IC ++ (Berndt et al., 2016). We validated that viral IC ++ expression in $N T S^{\mathrm{CeA}}$ neurons prevented action 

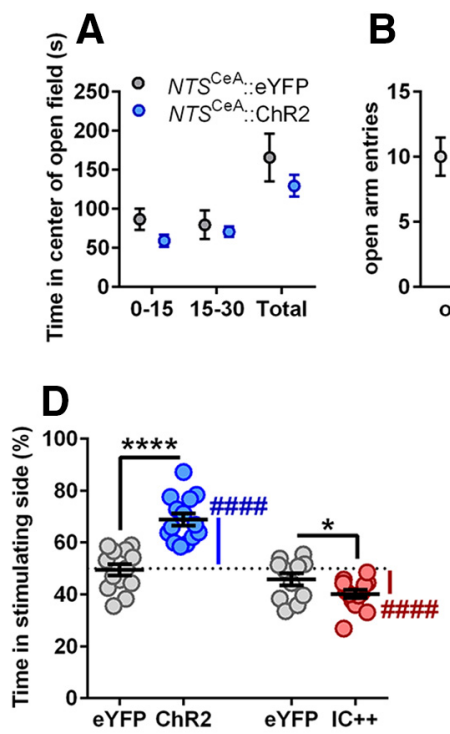

B

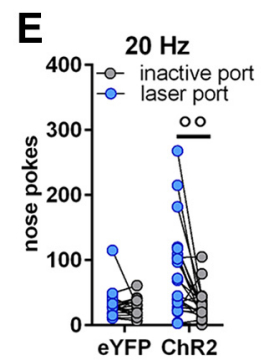

C
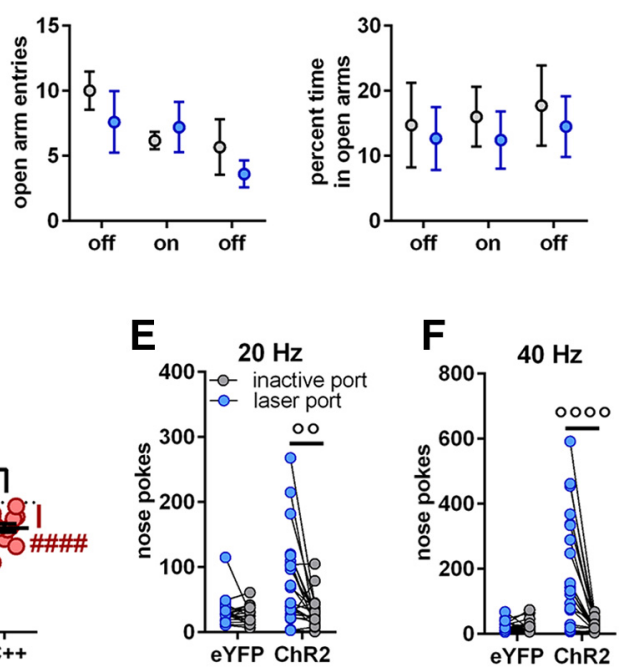

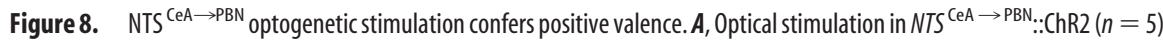
and NTS ${ }^{\mathrm{C} A} \rightarrow$ PBN.::eYFP mice $(n=4)$ did not change time spent in the center of an open field. $\boldsymbol{B}$, Optical stimulation in

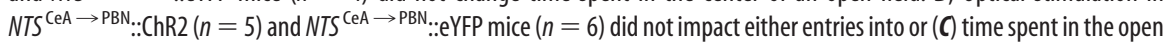

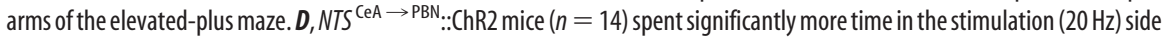

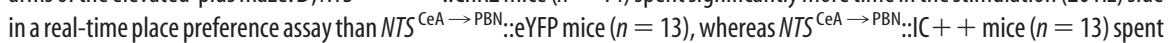

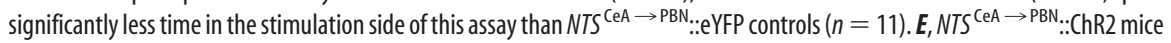

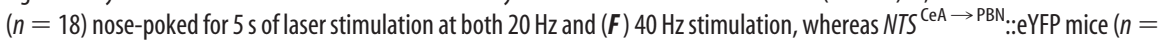
22) did not. Unpaired $t$ test: ${ }^{*} p \leq 0.05,{ }^{* * * *} p<0.0001$, One-sample $t$ test difference from $50 \%$ : ${ }^{\# \# \#} p<0.0001$; Bonferronicorrected paired $t$ test: ${ }^{\circ 0} p<0.001,{ }^{0000} p<0.0001$.

potential firing ex vivo (data not shown). When we expressed $\mathrm{IC}++$ in the CeA and placed fibers in the PBN $\left(N T S^{\mathrm{CeA} \rightarrow \mathrm{PBN}_{:}:}\right.$ IC ++- eYFP), mice showed a mild aversion to inhibition of the projection (constant light stimulation; Fig. $8 D$; unpaired $t$ test: $t_{(22)}=2.071, p=0.0503$ ). Congruently, we found that the

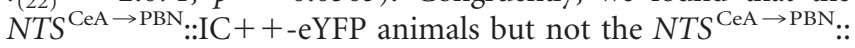
eYFP controls behaved significantly differently from chance (one-sample $t$ test, control: $t_{(10)}=1.774, p=0.1064$, IC ++ -

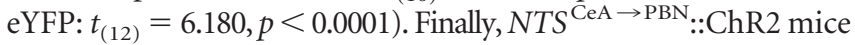
performed oICSS for $20 \mathrm{~Hz}$ (Fig. $8 E$; Bonferroni corrected $t$ test active vs active port: control: $t_{(34)}=0.930211, p=0.35882$; ChR2: $\left.t_{(42)}=3.19163, p=0.00268\right)$ as well as $40 \mathrm{~Hz}$ stimulation (Fig. 8F; Bonferroni corrected $t$ test active vs active port, control: $t_{(34)}=0.0708983, p=0.943894$; ChR2: $t_{(42)}=4.61353, p=$ 0.00004 ), demonstrating that activation of this pathway is intrinsically reinforcing. These data suggest that the NTS ${ }^{\mathrm{CeA} \rightarrow \mathrm{PBN}}$ pathway may bidirectionally modulate reward seeking behavior.

\section{Stimulation of the $N T S^{\mathrm{CeA} \rightarrow \mathrm{PBN}}$ projection promotes consumption of palatable fluids}

We next examined the impact of photostimulation on the con-

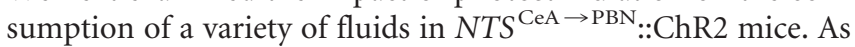
schematized in Figure 9A, mice were habituated to the chamber for $4 \mathrm{~d}$ and allowed to consume the test fluid for $3 \mathrm{~h}$ each day. Over the subsequent $4 \mathrm{~d}$, mice received $2 \mathrm{~d}$ of optical stimulation (noncontingent on the mouse's location) in 5 min cycles alternated with $2 \mathrm{~d}$ without stimulation, again for $3 \mathrm{~h}$ each day. Importantly, mice had food and water ad libitum during the entire course of the experiment, thus were not especially motivated to eat or drink.

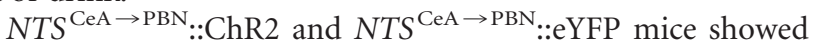
similar levels of ethanol drinking during habituation days (data not shown). We found that optical stimulation of the NTS ${ }^{\mathrm{CeA} \rightarrow \text { PBN }}$ pathway increased consumption of $6 \%$ ethanol (Fig. $9 B$; two-way ANOVA, interaction: $F_{(1,19)}$ $=7.363, p=0.0138$; virus type: $F_{(1,19)}=$ $0.01524, p=0.9031$; stimulation: $F_{(1,19)}=$ 3.665, $p=0.0707$; Bonferroni-corrected $t$ test, control: $t_{(19)}=0.5520, p>0.9999$; ChR2: $\left.t_{(19)}=3.353, p=0.0067\right)$ compared with non-stimulation days, whereas stimulation of $N T S^{\mathrm{CeA} \rightarrow \mathrm{PBN}}:$ :eYFP mice did not alter ethanol consumption. Examining only the days that the mice received

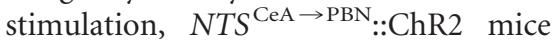
licked the bottle significantly more during the 5 min laser on versus laser off phases (Fig. 9G; two-way ANOVA, interaction: $F_{(1,19)}=6.117, p=0.0230$; virus type: $F_{(1,19)}=0.3760, p=0.5470$; stimulation: $F_{(1,19)}=5.890, p=0.0253$; Bonferronicorrected $t$ test, control: $t_{(19)}=0.03198$, $p>0.9999$; ChR2: $t_{(19)}=3.3551, p=$ $0.0043)$.

We next sought to determine whether this increase in ethanol consumption was due to a generalized increase in liquid consumption, or an ethanol-specific phenotype. In mice given ad libitum food and water, we performed the same experimental paradigm as in the previous experiment, but with water instead of ethanol. Stimulation of NTS ${ }^{\mathrm{CeA} \rightarrow \mathrm{PBN}}:: \mathrm{ChR} 2$ mice did not significantly alter water consumption (Fig. 9C; two-way ANOVA, interaction: $F_{(1,21)}=$ $1.901, p=0.1825$; virus type: $F_{(1,21)}=0.5904, p=0.4508$; stimulation: $\left.F_{(1,21)}=0.2757, p=0.6051\right)$. Interestingly, however, on

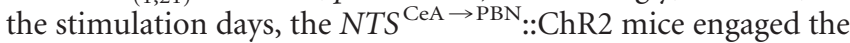
water bottle more during the 5 min laser stim epochs than the 5 min non-stim epochs (two-way ANOVA, interaction: $F_{(1,21)}=$ $8.591, p=0.0080$; virus type: $F_{(1,21)}=2.397, p=0.1365$; stimulation: $F_{(1,21)}=6.215, p=0.0211$; Bonferroni-corrected $t$ test, control: $t_{(21)}=0.3033, p>0.9999$; ChR2: $t_{(21)}=3.922, p=$ $0.0016)$. These results suggest that our optogenetic experiments are not manipulating a general fluid consumption pathway, like the neighboring NTS ${ }^{\mathrm{LH}}$ neuron population (Kurt et al., 2019), but perhaps a more selective circuit for which the appetitive properties of the available fluid is important.

To determine whether stimulation of the NTS ${ }^{\mathrm{CeA} \rightarrow \text { PBN }}$ projection would increase consumption of other palatable fluids, we performed the same experimental paradigm in the presence of

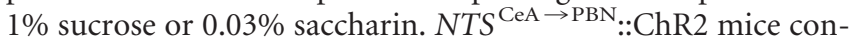
sumed significantly more sucrose solution on stimulation days (Fig. 9D; two-way ANOVA, interaction: $F_{(1,12)}=10.23, p=$ 0.0077 ; virus type: $F_{(1,12)}=2.584, p=0.1340$; stimulation: $F_{(1,12)}$ $=5.597, p=0.0357$; Bonferroni-corrected $t$ test, control: $t_{(12)}=$ $0.5884, p>0.9999$; ChR2: $\left.t_{(12)}=3.934, p=0.0040\right)$, and licked the bottle significantly more during stimulation epochs (Fig. 9I; two-way ANOVA, interaction: $F_{(1,12)}=15.92, p=0.0018$; virus type: $F_{(1,12)}=13.89, p=0.0029$; stimulation: $F_{(1,12)}=18.65, p=$ 0.0010; Bonferroni-corrected $t$ test, control: $t_{(12)}=0.2322, p>$

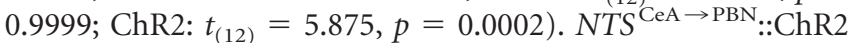
mice also consumed significantly more saccharin solution on stimulation days (Fig. 9E; two-way ANOVA, interaction: $F_{(1,12)}$ $=4.946, p=0.0461$; virus type: $F_{(1,12)}=1.490, p=0.2457$; 

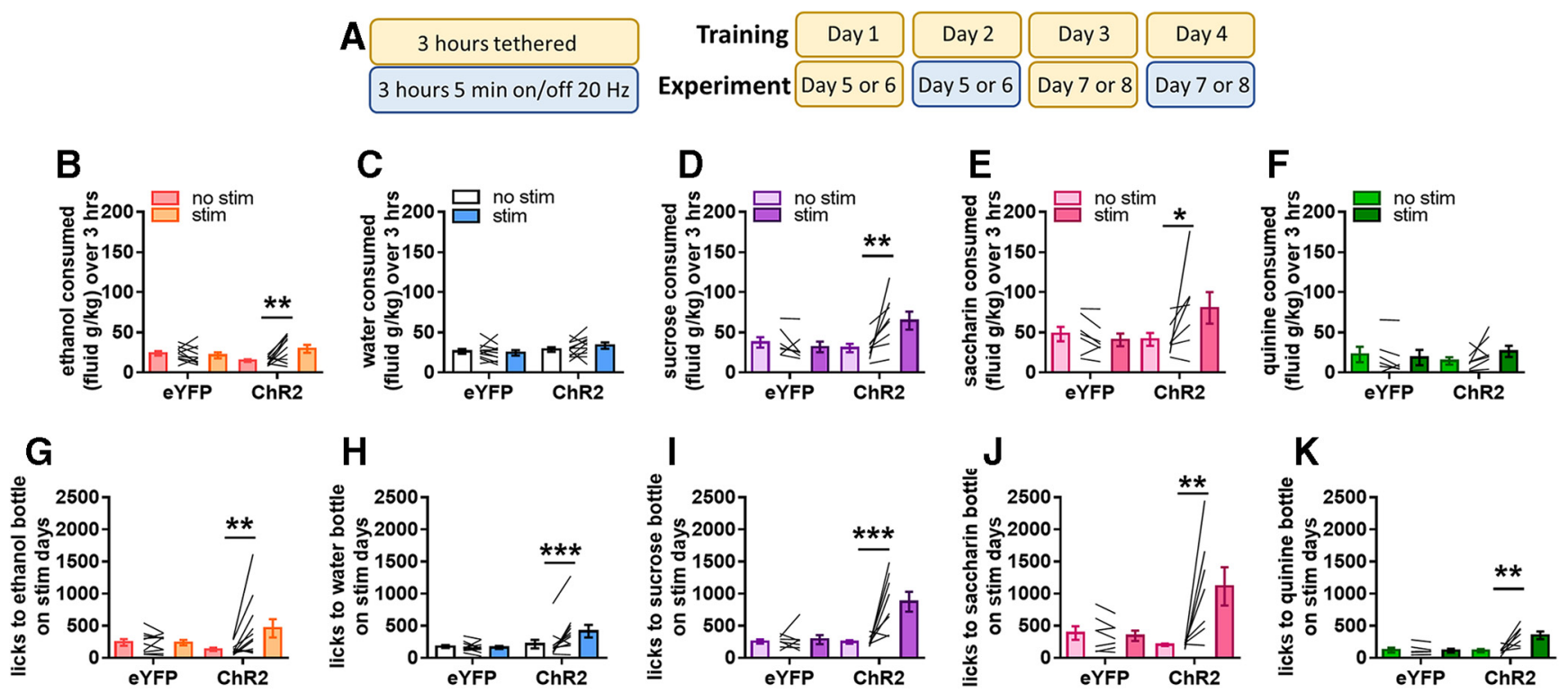

Figure 9. NTS ${ }^{\text {CeA } \rightarrow \text { PBN }}$ optogenetic stimulation promotes consumption of rewarding fluids. $A$, Schematic of optogenetic drinking paradigm. $B, N T S^{\mathrm{CeA}} \rightarrow$ PBN.::ChR2 mice $(n=11)$ drank

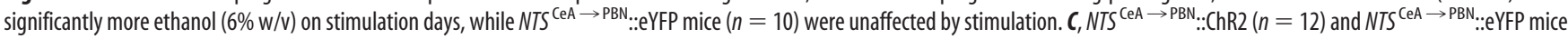

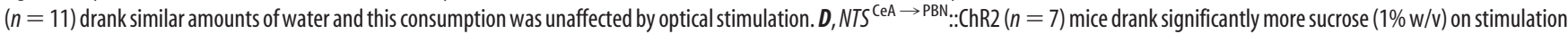

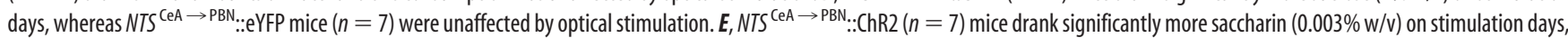

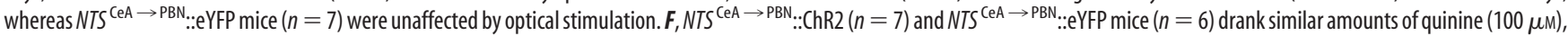
and this consumption was unaffected by optical stimulation. $\mathbf{G}-\boldsymbol{K}, N T S^{\mathrm{CeA} \rightarrow P B N} .:$.:ChR2 mice licked the bottle significantly more during stimulation epochs than during non-stimulation epochs in all conditions. Bonferroni-corrected paired $t$ test: ${ }^{*} p<0.05,{ }^{* *} p<0.01,{ }^{* * *} p<0.001$.

stimulation: $F_{(1,12)}=2.312, p=0.1543$; Bonferroni-corrected $t$ test: control $t_{(12)}=0.4975, p>0.9999 ;$ ChR2: $t_{(12)}=2.648, p=$ $0.0425)$, and licked the bottle more during stimulation epochs (Fig. 9J; two-way ANOVA, interaction: $F_{(1,12)}=9.380, p=$ 0.0099 ; virus type: $F_{(1,12)}=2.974, p=0.1103$; stimulation: $F_{(1,12)}$ $=7.776, p=0.0164$; Bonferroni-corrected $t$ test, control: $t_{(12)}=$ $0.1938, p>0.9999$; ChR2: $\left.t_{(12)}=4.137, p=0.0028\right)$, indicating that the increase in consumption is not dependent on the caloric content of the solution.

We then performed the same experiment using a $100 \mu \mathrm{M}$ quinine solution to determine whether NTS ${ }^{\mathrm{CeA} \rightarrow \text { PBN }}$ stimulation would affect consumption of negative valence tastants. Stimulation failed to increase quinine drinking on stim versus no-stim days (Fig. 9F; two-way ANOVA, interaction: $F_{(1,11)}=3.137, p=$ 0.1042 ; virus type: $F_{(1,11)}=0.0003, p=0.9859$; stimulation: $\left.F_{(1,11)}=0.8933, p=0.3649\right)$, but increased licking during stim versus no-stim epochs (Fig. $9 \mathrm{~K}$; two-way ANOVA, interaction: $F_{(1,11)}=9.798, p=0.0096$; virus type: $F_{(1,11)}=7.165 ., p=$ 0.0215 ; stimulation: $F_{(1,11)}=8.360 ., p=0.0147$; Bonferronicorrected $t$ test, control: $t_{(11)}=0.1628, p>0.9999$; ChR2: $t_{(11)}=$ $4.432, p=0.0020)$. Together, these data suggest that stimulation of the NTS-CeA to PBN pathway increases consumption of rewarding fluids.

We next reanalyzed the videos from three of the consumption experiments (water-neutral, sucrose-palatable, and quinineaversive) to validate the automated licking results. This was particularly important due to the discrepancy between the findings that $N T S^{\mathrm{CeA} \rightarrow \mathrm{PBN}}$ stimulation increases bottle interaction regardless of fluid content (Fig. 9G-K), but only increases consumption on days when the bottle contains a palatable/rewarding fluid (Fig. 9B-F). We hand scored bottle-licking behavior and found that indeed NTS ${ }^{\mathrm{CeA} \rightarrow \mathrm{PBN}}:: \mathrm{ChR} 2$ animals licked the bottle more on average during laser stimulation-on epochs regardless of whether the bottle contained water (Fig. 10A; two-way ANOVA, interaction: $F_{(1,19)}=10.14, p=0.0049$; virus type: $F_{(1,19)}=6.001$, $p=0.0242$; stimulation: $F_{(1,19)}=10.52, p=0.0043$; Bonferronicorrected $t$ test, control: $t_{(19)}=0.04096, p>0.9999$; ChR2: $t_{(19)}=$ $4.658, p=0.0003$ ), sucrose (Fig. 10B; two-way ANOVA, interaction: $F_{(1,13)}=10.27, p=0.0069$; virus type: $F_{(1,13)}=11.80, p=$ 0.0044 ; stimulation: $F_{(1,13)}=11.80, p=0.5824$; Bonferronicorrected $t$ test, control: $t_{(13)}=0.1570, p>0.9999$; ChR2: $t_{(13)}=$ $4.860, p=0.0006$ ), or quinine (Fig. $10 C$; two-way ANOVA, interaction: $F_{(1,11)}=0.6329, p=0.0287$; virus type: $F_{(1,11)}=$ 0.2777, $p=0.6087$; stimulation: $F_{(1,11)}=4.107, p=0.0676$; Bonferroni-corrected $t$ test, control: $t_{(11)}=0.3333, p>0.9999$; ChR2: $\left.t_{(11)}=3.343, p=0.0131\right)$. These data reinforce the idea that stimulation of the NTS ${ }^{\mathrm{CeA} \rightarrow \mathrm{PBN}}$ pathway increases licking behavior, but that the relationship between licking behavior and fluid consumption is not $1: 1$.

Previous work exploring the $H \operatorname{tr} 2 a^{\mathrm{CeA} \rightarrow \mathrm{PBN}}$ projection in consumption showed that optogenetic stimulation of this pathway increased the duration of feeding bouts (Douglass et al., 2017). We thus examined whether the number and/or duration of drinking bouts were affected with stimulation of the NTS ${ }^{\mathrm{CeA} \rightarrow \mathrm{PBN}}$ pathway. When we examined the number of drinking bouts across the whole $3 \mathrm{~h}$, we found that

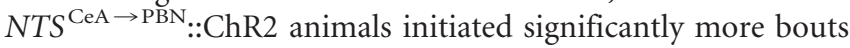
during laser-on epochs regardless of whether the bottle contained water (Fig. 10D; two-way ANOVA, interaction: $F_{(1,19)}=4.643$, $p=0.0442$; virus type: $F_{(1,19)}=2.062, p=0.1673$; stimulation: $F_{(1,19)}=6.764, p=0.0176$; Bonferroni-corrected $t$ test, control: $t_{(19)}=0.3081, p>0.9999 ;$ ChR2: $\left.t_{(19)}=3.446, p=0.0054\right)$, sucrose (Fig. 10E; two-way ANOVA, interaction: $F_{(1,13)}=7.675$, $p=0.0159$; virus type: $F_{(1,13)}=6.283, p=0.0263$; stimulation: $F_{(1,13)}=10.95, p=0.0057$; Bonferroni-corrected $t$ test, control: $t_{(13)}=0.3687, p>0.9999$; ChR2: $\left.t_{(13)}=4.45, p=0.0013\right)$, or quinine (Fig. 10F; two-way ANOVA, interaction: $F_{(1,11)}=7.126$, $p=0.0218$; virus type: $F_{(1,11)}=0.2517, p=0.6258$; stimulation: 

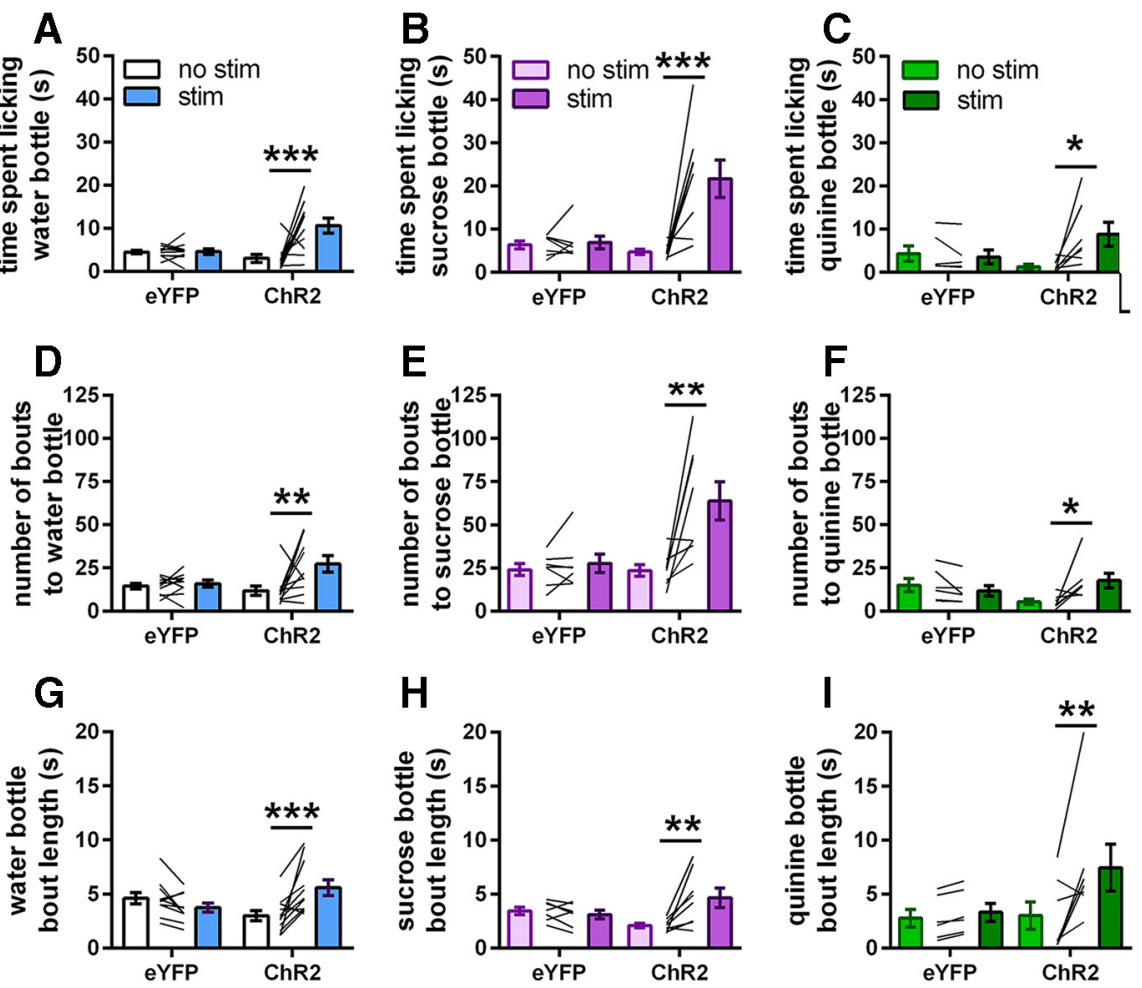

Figure 10. NTS ${ }^{\mathrm{CeA} \rightarrow \mathrm{PBN}}$ optogenetic stimulation increases licking by increasing both bout length and number. $\boldsymbol{A}-\boldsymbol{C}$,

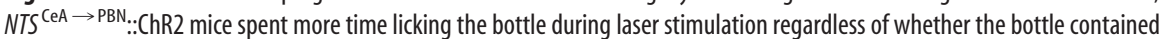

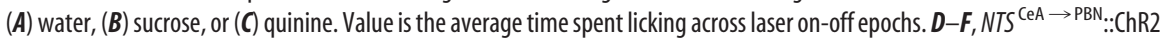
mice had a higher number of drinking bouts regardless of whether the bottle contained $(\boldsymbol{D})$ water, $(\boldsymbol{E})$ sucrose, or $(\boldsymbol{F})$ quinine. $\mathbf{G}-\boldsymbol{I}$,

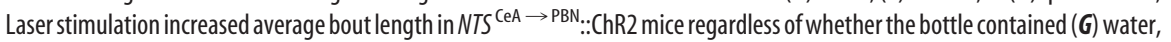
$(\boldsymbol{H})$ sucrose, or $(\boldsymbol{I})$ quinine. Bonferroni-corrected paired $t$ test: ${ }^{*} p<0.05,{ }^{* *} p<0.01,{ }^{* *} 0.001$.

$F_{(1,11)}=2.273, p=0.1598$; Bonferroni-corrected $t$ test, control: $t_{(11)}=0.7916, p=0.8907$; ChR2: $\left.t_{(11)}=3.074, p=0.0212\right)$. We found that stimulation also increased average bout length in

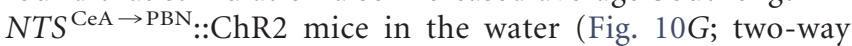
ANOVA, interaction: $F_{(1,19)}=16.03, p=0.0008$; virus type: $F_{(1,19)}=0.03605, p=0.8514$; stimulation: $F_{(1,19)}=3.896, p=$ 0.0631; Bonferroni-corrected $t$ test, control: $t_{(19)}=1.403, p=$ 0.3537; ChR2: $t_{(19)}=4.331, p=0.0007$ ), sucrose (Fig. $10 H$; twoway ANOVA, interaction: $F_{(1,13)}=9.659, p=0.0083$; virus type: $F_{(1,13)}=0.02477$., $p=0.8774$; stimulation: $F_{(1,13)}=5.637, p=$ 0.0337; Bonferroni-corrected $t$ test, control: $t_{(13)}=0.5022, p>$ 0.9999; ChR2: $\left.t_{(13)}=4.013, p=0.0030\right)$, and quinine conditions (Fig. 10I; two-way ANOVA, interaction: $F_{(1,11)}=4.571, p=$ 0.0558 ; virus type: $F_{(1,11)}=1.372, p=0.2663$; stimulation: $F_{(1,11)}$ $=7.532, p=0.0191$; Bonferroni-corrected $t$ test, control: $t_{(11)}=$ 0.4132, $p>0.9999$; ChR2: $\left.t_{(11)}=3.593, p=0.0084\right)$. Thus, our data demonstrate that even when total liquid consumption is not altered by stimulation (water/quinine), the stimulation of this pathway promotes multiple behaviors associated with the seeking of fluids.

\section{Stimulation of the $N T S^{\mathrm{CeA} \rightarrow \mathrm{PBN}}$ projection fails to impact consumption of solid foods under most conditions}

The PBN has a well described role in appetite suppression (Carter et al., 2013). Indeed, recent work describing a CeA to PBN projection indicates that GABAergic input from the CeA can promote food consumption (Douglass et al., 2017). Suppression of PBN anorexigenic neuronal ensembles could explain the increase in palatable fluid consumption observed in the previous experiments. If this were the case, however, we would expect stimulation of the $N T S{ }^{\mathrm{CeA} \rightarrow \text { PBN }}$ pathway to induce an overall increase in consumption, reflected in chow intake over this same period. Stimulation of the $N T S^{\mathrm{CeA}} \rightarrow$ PBN pathway failed to impact chow consumption in the presence of water (Fig. 11A; two-way ANOVA, interaction: $F_{(1,21)}=0.03704$, $p=0.8492$; virus type: $F_{(1,21)}=0.003276$, $p=0.9549$; stimulation: $F_{(1,21)}=3.223$, $p=0.0870$ ), sucrose (Fig. $11 B$; two-way ANOVA, interaction: $F_{(1,12)}=1.981, p=$ 0.1846 ; virus type: $F_{(1,12)}=0.8698, p=$ 0.3694 ; stimulation: $F_{(1,12)}=0.1347, p=$ 0.7200 ), saccharin (Fig. 11C; two-way ANOVA, interaction: $F_{(1,12)}=0.008336$, $p=0.9288$; virus type: $F_{(1,12)}=0.4687$, $p=0.5066$; stimulation: $F_{(1,12)}=1.952$, $p=0.1876$ ) or quinine (Fig. $11 D$; twoway ANOVA, interaction: $F_{(1,11)}=$ $0.02909, p=0.8677$; virus type: $F_{(1,11)}=$ $0.1673, p=0.6904$; stimulation: $F_{(1,11)}=$ $0.001504, p=0.9698)$. Surprisingly, in the presence of ethanol, however, NTS ${ }^{\mathrm{CeA} \rightarrow \mathrm{PBN}}$ :: ChR2 mice decreased chow consumption on days when they received stimulation (Fig. 11E; two-way ANOVA, interaction: $F_{(1,22)}=4.313, p=0.0497$; virus type: $F_{(1,22)}=0.5391, p=0.4705$; stimulation: $F_{(1,22)}=7.387, p=0.0126$; Bonferronicorrected $t$ test, control: $t_{(19)}=0.1007$, $p>0.9999$; ChR2: $t_{(19)}=2.956, p=$ $0.0162)$. Taken as a whole these data indicate that the NTS ${ }^{\mathrm{CeA} \rightarrow \mathrm{PBN}}$ projection is involved with rewarding fluid intake as opposed to general consumption.

Because optical stimulation of the NTS ${ }^{\mathrm{CeA} \rightarrow \mathrm{PBN}}$ promoted the consumption of sweet fluids, we then examined whether stimulation of this projection would impact consumption of a familiar sugary solid food. Two days after home-cage exposure to Froot Loops, NTS ${ }^{\mathrm{CeA} \rightarrow \mathrm{PBN}}:: \mathrm{ChR} 2$ animals were allowed to consume Froot Loops ad libitum for $10 \mathrm{~min}$. Optical stimulation of the NTS ${ }^{\mathrm{CeA} \rightarrow \text { PBN }}$ did not impact Froot Loops consumption (Fig. $10 F$; two-way ANOVA, interaction: $F_{(1,11)}=0.01094, p=0.9186$; virus type: $F_{(1,11)}=4.714, p=0.0527$; stimulation: $F_{(1,11)}=$ $0.007948, p=0.9306)$. To determine whether increasing the motivation to eat would perhaps reveal a role for this projection in palatable food consumption, we repeated this experiment following $24 \mathrm{~h}$ of food restriction. Under these conditions stimulation failed to impact Froot Loops consumption (Fig. 10G; unpaired $t$ test: $\left.t_{(23)}=0.7030, p=0.4891\right)$. Together, these data demonstrate a role for the NTS ${ }^{\mathrm{CeA} \rightarrow \mathrm{PBN}}$ projection in promoting the consumption of palatable fluids, disassociated from the $\mathrm{CeA}$ and $\mathrm{PBN}^{\prime}$ s respective reported roles in solid food consumption.

\section{Discussion}

The CeA regulates several behaviors associated with alcohol use disorders. The particular genetically defined cell types and circuits that mediate these behaviors, however, are poorly understood. Here we have shown that NTS-expressing neurons in the CeA contribute to voluntary ethanol consumption in nonalcohol-dependent mice. Additionally, our data demonstrate 
A

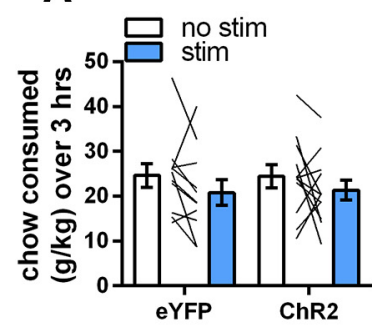

E

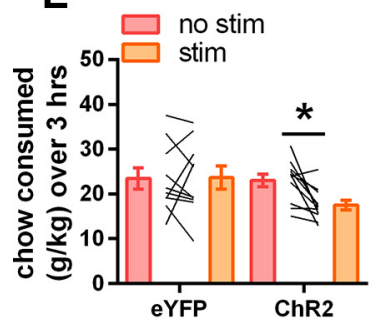

B

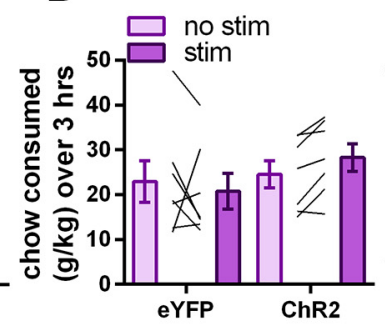

$\mathbf{F}$

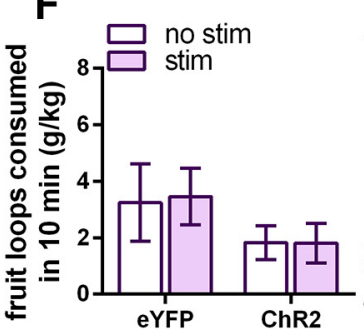

C

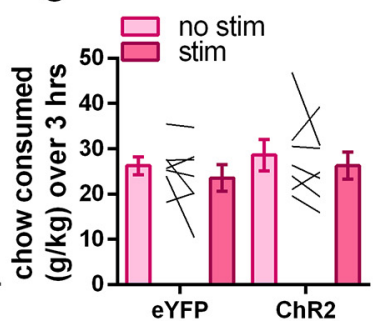

G

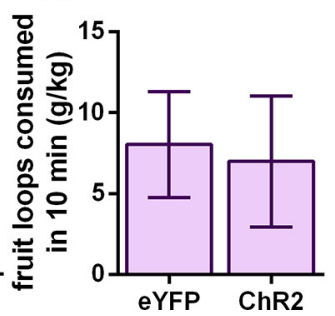

D

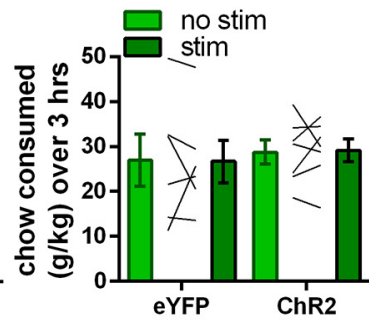

Figure 11. NTS ${ }^{\mathrm{CeA} \rightarrow \mathrm{PBN}}$ optogenetic stimulation does not alter consumption of solid foods under most conditions. $\boldsymbol{A}-\boldsymbol{E}$, Chow consumed during the optogenetic experiment outlined in Figure

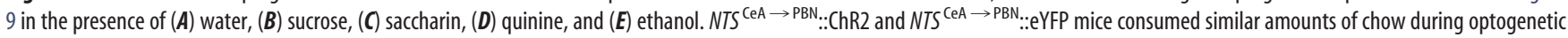
stimulation. $\boldsymbol{E}$, NTS ${ }^{\mathrm{CeA} \rightarrow P B N}:$ :ChR2 mice ate less chow on stimulation days when ethanol was present. $\boldsymbol{F}$, Stimulation failed to impact Froot Loop consumption during a 10 min session regardless of whether the animals were sated (eYFP $n=6, \mathrm{ChR} 2 n=7$ ) or $(\boldsymbol{G})$ following $24 \mathrm{~h}$ food restriction (eYFP $n=11$, ChR2 $n=14$ ). Bonferroni-corrected paired $t$ test: ${ }^{*} p<0.05$.

that a subset of these neurons project to the $\mathrm{PBN}$, that stimulation of this projection is positively reinforcing (supporting RTPP and oICSS), and leads to increased consumption of palatable fluids and ethanol.

\section{CeA neurotensin neurons in ethanol consumption}

The CeA is well known to be engaged by ethanol consumption and is implicated in mediating both the negative and positive reinforcing properties of ethanol (Koob et al., 1998; Koob, 2015). In keeping with this, early studies found that pharmacological inhibition of $\mathrm{GABA}_{\mathrm{A}}$ receptors in (Hyytiä and Koob, 1995), and chemical lesions of (Möller et al., 1997), the CeA reduce ethanol consumption without affecting water consumption. Our data show that relatively low in vivo ethanol consumption can activate $N t{ }^{\mathrm{CeAL}}$ neurons (Fig. $6 \mathrm{~F}$ ), and that selectively lesioning $N T S^{\mathrm{CeA}}$ neurons decreases ethanol intake and preference, without altering consumption of other fluids (Figs. 3, 5). Concordant with this finding, optogenetic stimulation of the NTS ${ }^{\mathrm{CeA} \rightarrow \mathrm{PBN}}$ projection increased ethanol consumption (Fig. 9B), but again did not alter consumption of water or quinine solutions (Fig. 9C,F). Future work will examine which aspects of NTS ${ }^{\mathrm{CeA}}$ signaling, such as GABA, NTS, and/or other peptides, are responsible for these results.

Studies conducted in animals dependent on, or consuming binge quantities of, ethanol have identified CeA CRF signaling and CRF ${ }^{\mathrm{CeA}}$ neurons as a locus of ethanol effects on GABA transmission (Nie et al., 2004; Lowery-Gionta et al., 2012; Pleil et al., 2015; Herman et al., 2016; de Guglielmo et al., 2019). In fact, a recent study from de Guglielmo et al. (2019) showed that inhibition of the $\mathrm{Crh}^{\mathrm{CeA} \rightarrow \mathrm{BNST}}$ projection in ethanol-dependent rats decreased ethanol intake and symptoms of somatic withdrawal, illustrating the potential of these neurons to mediate negative reinforcing aspects of ethanol consumption. Our data and others (Kim et al., 2017; McCullough et al., 2018) indicate that Nts ${ }^{\mathrm{CeA}}$ neurons are a subset of $\mathrm{Crh}^{\mathrm{CeA}}$ and $\mathrm{Crh} 1^{\mathrm{CeA}}$ neurons, suggesting that other genetically-overlapping CeA projections may also be modulated by a history of ethanol consumption.

$N t s^{\mathrm{CeA}}$ neurons also have a partial overlap with $P d y n{ }^{\mathrm{CeA}}$ neurons. Dynorphin neurons in the CeA contribute to binge- drinking, a form of ethanol consumption that confers a high risk of developing alcohol use disorder (Anderson et al., 2019). We recently showed that dynorphin and NTS bidirectionally modulate synaptic inputs from the CeA to the BNST (Normandeau et al., 2018). This phenomenon may also be relevant to intra-CeA signaling, as well as $\mathrm{CeA} \rightarrow \mathrm{PBN}$ projections, and provide yet another mechanism for ethanol-induced plasticity in this circuit. Because of these data, we hypothesize that multiple CeA populations, including the NTS ${ }^{\mathrm{CeA} \rightarrow \mathrm{PBN}}$ projection, may mediate early positive reinforcement and therefore could facilitate the transition into dependence. Although we were surprised that manipulation of $N T S^{C e A}$ neurons did not alter anxiety-like behavior, we also hypothesize that these neurons may play different roles depending on the state of the animal (e.g., stress, dependence, intoxication, thirst).

\section{Ethanol consumption and appetite}

We found that stimulation of the NTS ${ }^{\mathrm{CeA} \rightarrow \text { PBN }}$ pathway decreased food consumption when ethanol was available. Ethanol consumption and appetite have a complex relationship that has not been fully parsed (Cains et al., 2017), and food consumption may impact subjective perceptions of the effects of ethanol consumption (Caton et al., 2007). Previous ex vivo studies have shown that the CeA is a site of action for the pharmacological effects of both ghrelin and ethanol (Cruz et al., 2013), suggesting that this may be a site of interplay between appetite and ethanol. Because of limitations of our experimental design, we were not able to explore this finding, but believe that further work examining this relationship in the context of the NTS ${ }^{\mathrm{CeA} \rightarrow \mathrm{PBN}}$ circuit is promising.

CeA neurotensin neurons promote positive valence behaviors There is a general hypothesis that the CeA has a role in amplifying motivation for reward-seeking but does not have a direct role in reward in and of itself. This is largely because nonspecific optical CeA stimulation increases responding for a laser-paired positive reinforcer and can shift preference toward a non-preferred paired outcome (Robinson et al., 2014; Warlow et al., 2017). However, 
this manipulation does not support intracranial self-stimulation behavior for unpaired stimulation. On the other hand, our results demonstrating that optical stimulation of the $N T S^{\mathrm{CeA} \rightarrow \text { PBN }}$ pathway is reinforcing is consistent with recent data showing that NTS+ neurons in the CeA promote positive valence (Kim et al., 2017). While Kim et al. (2017) divided the NTS ${ }^{\mathrm{CeA}}$ population into two groups, mice performed nose-poking behavior for cellbody stimulation for both of these subpopulations.

Because the CeA is composed of a heterogeneous population of neurons expressing multiple neuropeptides/signaling molecules, projecting both within the nucleus and across the brain, we suggest that stimulation of the CeA as a whole may obscure the role of specific projections or genetically-defined subtypes, particularly if they have reciprocal inhibitory connections within the CeA. In addition to Kim et al. (2017), other work in $\mathrm{CeA} \rightarrow \mathrm{PBN}$ projections from genetically-defined subtypes, such as Htr2a (serotonin 2 a receptor) and Pnoc (prepronociceptin), have shown that stimulation can support nose-poking behavior (Douglass et al., 2017; Hardaway et al., 2019). Another explanation may be that most of the experiments examining genetically-defined CeA populations have been conducted in mice, whereas studies stimulating the CeA as a whole have largely been performed in rats (but see de Guglielmo et al., 2019).

Our finding that stimulation of the NTS ${ }^{\mathrm{CeA} \rightarrow \mathrm{PBN}}$ projection can both promote positive valence behaviors and increase consummatory behaviors are at first counterintuitive. Indeed, much work elucidating the neural circuits of feeding has described circuits that promote consumption through negative valence signals encoding hunger and thirst states (Betley et al., 2015). However, we are not alone in describing an amygdala-to-PBN circuit fulfilling both of these criteria. Recent experiments describe a CeA Htr2a-containing population that promotes food consumption (Douglass et al., 2017), which may overlap with the Nts population (Kim et al., 2017; Torruella-Suarez, data not shown). These circuits may underlie hedonic consumption, a form of consumption that has particular implications for the obesity epidemic (Lowe and Butryn, 2007).

\section{Palatable fluid consumption: implications for sweetened beverages}

Although we show here that ablation of NTS ${ }^{\mathrm{CeA}}$ neurons failed to impact preference for sweet or bitter fluids, stimulation of the $N T S$ CeA $\rightarrow$ PBN projection increased consumption of a variety of palatable fluids, and revealed a role for this neuronal population in palatable fluid consumption. Our results, however, are markedly different to other fluid circuits that have been described within relevant NTS-neuron and PBN circuity. Oxtr ${ }^{\mathrm{PBN}}$ neurons appear to signal overall fluid satiation (Ryan et al., 2017), whereas stimulation of $N T S^{\mathrm{LH}}$ neurons increases fluid consumption, regardless of the identity of the available fluid (Kurt et al., 2019). In contrast, our data demonstrate that ablation of the NTS ${ }^{\mathrm{CeA}}$ neurons does not alter gross fluid consumption. Although we do not know the precise identity of the neurons in the PBN that receive input from the NTS ${ }^{\mathrm{CeA}}$ neurons, future work to classify which population is inhibited by the NTS ${ }^{\mathrm{CeA}}$ will undoubtedly be very informative as to how this circuit regulates the consumption of palatable fluids.

Although the current obesity epidemic clearly has a variety of causes, sweetened beverages have emerged as an important target for both study and policy intervention by concerned government entities (Fowler et al., 2008; Malik et al., 2013; Centers for Disease Control and Prevention, 2017). Interestingly, ethanol has a sweet taste component in both humans and C57BL/6J mice (Scinska et al., 2000; Blizard, 2007), which may account for why stimulation of the NTS ${ }^{\mathrm{CeA} \rightarrow \mathrm{PBN}}$ pathway promoted its consumption. In contrast, caspase ablation of the NTS ${ }^{\mathrm{CeA}}$ neurons impaired ethanol consumption without affecting sucrose or saccharin preference, which, in conjunction with our results showing that sucrose consumption elevated Fos in the $\mathrm{CeA}_{\mathrm{M}}$, suggests that there may be redundant circuitries that compensate for the drive to consume sweet beverages. Regardless, it is worth noting that consumption of alcoholic beverages by people almost always includes sweeteners. The connection between ethanol and sweet liquid consumption in our data presents an additional convergence between these consummatory behaviors, and future experiments will focus on understanding how sweet beverages and ethanol contribute to adaptations within this pathway.

Here we describe a genetically defined population of CeA neurons, $N T S^{\mathrm{CeA}}$, that are activated by ethanol drinking in vivo, and whose ablation impairs ethanol consumption and preference. Optical stimulation of the NTS ${ }^{\mathrm{CeA}} \rightarrow$ PBN projection conferred a positive valence and increased consumption of rewarding fluids such as sweet flavored and ethanol solutions. Stimulation of this projection did not increase consumption of neutral or aversive fluids, impact consumption of solid food (with the intriguing exception of ethanol/chow choice) or affect anxiety-like behaviors. This work highlights the NTS ${ }^{\mathrm{CeA} \rightarrow \mathrm{PBN}}$ pathway as a fundamental circuit in promoting drinking behavior, and suggests that further examination of this pathway is relevant for the study of motivation to consume in the context of obesity and alcohol use disorders.

\section{References}

Anderson RI, Lopez MF, Griffin WC, Haun HL, Bloodgood DW, Pati D, Boyt KM, Kash TL, Becker HC (2019) Dynorphin-kappa opioid receptor activity in the central amygdala modulates binge-like alcohol drinking in mice. Neuropsychopharmacology 44:1084-1092.

Berndt A, Lee SY, Wietek J, Ramakrishnan C, Steinberg EE, Rashid AJ, Kim H, Park S, Santoro A, Frankland PW, Iyer SM, Pak S, Ährlund-Richter S, Delp SL, Malenka RC, Josselyn SA, Carlén M, Hegemann P, Deisseroth K (2016) Structural foundations of optogenetics: determinants of channelrhodopsin ion selectivity. Proc Natl Acad Sci U S A 113:822-829.

Betley JN, Xu S, Cao ZFH, Gong R, Magnus CJ, Yu Y, Sternson SM (2015) Neurons for hunger and thirst transmit a negative-valence teaching signal. Nature 521:180-185.

Binder EB, Kinkead B, Owens MJ, Nemeroff CB (2001) Neurotensin and dopamine interactions. Pharmacol Rev 53:453-486.

Blizard DA (2007) Sweet and bitter taste of ethanol in C57BL/6J and DBA2/J mouse strains. Behav Genet 37:146-159.

Cáceda R, Kinkead B, Nemeroff CB (2006) Neurotensin: role in psychiatric and neurological diseases. Peptides 27:2385-2404.

Cai H, Haubensak W, Anthony TE, Anderson DJ (2014) Central amygdala PKC- $\delta+$ neurons mediate the influence of multiple anorexigenic signals. Nat Neurosci 17:1240-1248.

Cains S, Blomeley C, Kollo M, Rácz R, Burdakov D (2017) Agrp neuron activity is required for alcohol-induced overeating. Nat Commun 8:14014.

Carter ME, Soden ME, Zweifel LS, Palmiter RD (2013) Genetic identification of a neural circuit that suppresses appetite. Nature 503:111-114.

Carter ME, Han S, Palmiter RD (2015) Parabrachial calcitonin gene-related peptide neurons mediate conditioned taste aversion. J Neurosci 35:45824586 .

Caton SJ, Bate L, Hetherington MM (2007) Acute effects of an alcoholic drink on food intake: aperitif versus co-ingestion. Physiol Behav 90:368375.

Centers for Disease Control and Prevention (2017) Get the facts: sugarsweetened beverages and consumption. Available at https://www. cdc.gov/nutrition/data-statistics/sugar-sweetened-beverages-intake. html.

Chang SL, Patel NA, Romero AA (1995) Activation and desensitization of 
fos immunoreactivity in the rat brain following ethanol administration. Brain Res 679:89-98.

Chavkin C, James IF, Goldstein A (1982) Dynorphin is a specific endogenous ligand of the kappa opioid receptor. Science 215:413-415.

Cruz MT, Herman MA, Cote DM, Ryabinin AE, Roberto M (2013) Ghrelin increases GABAergic transmission and interacts with ethanol actions in the rat central nucleus of the amygdala. Neuropsychopharmacology 38:364-375.

de Guglielmo G, Kallupi M, Pomrenze MB, Crawford E, Simpson S, Schweitzer P, Koob GF, Messing RO, George O (2019) Inactivation of a CRF-dependent amygdalofugal pathway reverses addiction-like behaviors in alcohol-dependent rats. Nat Commun 10:1238.

Douglass AM, Kucukdereli H, Ponserre M, Markovic M, Gründemann J, Strobel C, Alcala Morales PL, Conzelmann KK, Lüthi A, Klein R (2017) Central amygdala circuits modulate food consumption through a positive valence mechanism. Nat Neurosci 20:1384-1394.

Edwards GL, Johnson AK (1991) Enhanced drinking after excitotoxic lesions of the parabrachial nucleus in the rat. Am J Physiol 261:R1039R1044.

Fitzpatrick K, Winrow CJ, Gotter AL, Millstein J, Arbuzova J, Brunner J, Kasarskis A, Vitaterna MH, Renger JJ, Turek FW (2012) Altered sleep and affect in the neurotensin receptor 1 knockout mouse. Sleep 35: 949-956.

Fowler SP, Williams K, Resendez RG, Hunt KJ, Hazuda HP, Stern MP (2008) Fueling the obesity epidemic? Artificially sweetened beverage use and long-term weight gain. Obesity 16:1894-1900.

Gilpin NW, Stewart RB, Murphy JM, Badia-Elder NE (2004) Neuropeptide $\mathrm{Y}$ in the paraventricular nucleus of the hypothalamus increases ethanol intake in high- and low-alcohol-drinking rats. Alcohol Clin Exp Res 28: 1492-1498.

Gilpin NW, Herman MA, Roberto M (2015) The central amygdala as an integrative hub for anxiety and alcohol use disorders. Biol Psychiatry 77:859-869.

Grigson PS, Reilly S, Shimura T, Norgren R (1998) Ibotenic acid lesions of the parabrachial nucleus and conditioned taste aversion: further evidence for an associative deficit in rats. Behav Neurosci 112:160-171.

Hardaway JA, Halladay LR, Mazzone CM, Pati D, Bloodgood DW, Kim M, Jensen J, DiBerto JF, Boyt KM, Shiddapur A, Erfani A, Hon OJ, Neira S, Stanhope CM, Sugam JA, Saddoris MP, Tipton G, McElligott Z, Jhou TC, Stuber GD, et al. (2019) Central amygdala prepronociceptin-expressing neurons mediate palatable food consumption and reward. Neuron 102: 1037-1052.e7.

Haubensak W, Kunwar PS, Cai H, Ciocchi S, Wall NR, Ponnusamy R, Biag J, Dong HW, Deisseroth K, Callaway EM, Fanselow MS, Lüthi A, Anderson DJ (2010) Genetic dissection of an amygdala microcircuit that gates conditioned fear. Nature 468:270-276.

Herman MA, Contet C, Roberto M (2016) A functional switch in tonic GABA currents alters the output of central amygdala corticotropin releasing factor receptor-1 neurons following chronic ethanol exposure. J Neurosci 36:10729-10741.

Hwa LS, Chu A, Levinson SA, Kayyali TM, DeBold JF, Miczek KA (2011) Persistent escalation of alcohol drinking in C57BL/6J mice with intermittent access to $20 \%$ ethanol: escalated alcohol after intermittent access. Alcohol Clin Exp Res 35:1938-1947.

Hyytiä P, Koob GF (1995) GABAA receptor antagonism in the extended amygdala decreases ethanol self-administration in rats. Eur J Pharmacol 283:151-159.

Kelley SP, Nannini MA, Bratt AM, Hodge CW (2001) Neuropeptide-Y in the paraventricular nucleus increases ethanol self-administration. Peptides 22:515-522.

Kempadoo KA, Tourino C, Cho SL, Magnani F, Leinninger GM, Stuber GD, Zhang F, Myers MG, Deisseroth K, de Lecea L, Bonci A (2013) Hypothalamic neurotensin projections promote reward by enhancing glutamate transmission in the VTA. J Neurosci 33:7618-7626.

Kim J, Zhang X, Muralidhar S, LeBlanc SA, Tonegawa S (2017) Basolateral to central amygdala neural circuits for appetitive behaviors. Neuron 93: 1464-1479.e5.

Koob GF (2015) The dark side of emotion: the addiction perspective. Eur J Pharmacol 753:73-87.

Koob GF, Sanna PP, Bloom FE (1998) Neuroscience of addiction. Neuron 21:467-476.

Kurt G, Woodworth HL, Fowler S, Bugescu R, Leinninger GM (2019) Acti- vation of lateral hypothalamic area neurotensin-expressing neurons promotes drinking. Neuropharmacology 154:13-21.

Lee MR, Hinton DJ, Song JY, Lee KW, Choo C, Johng H, Unal SS, Richelson E, Choi DS (2010) Neurotensin receptor type 1 regulates ethanol intoxication and consumption in mice. Pharmacol Biochem Behav 95: 235-241.

Lee MR, Hinton DJ, Unal SS, Richelson E, Choi DS (2011) Increased ethanol consumption and preference in mice lacking neurotensin receptor type 2: neurotensin receptor type 2 and alcoholism. Alcohol Clin Exp Res 35:99-107.

Leggio L (2010) Role of the ghrelin system in alcoholism: acting on the growth hormone secretagogue receptor to treat alcohol-related diseases. Drug News Perspect 23:157-166.

Leinninger GM, Opland DM, Jo YH, Faouzi M, Christensen L, Cappellucci LA, Rhodes CJ, Gnegy ME, Becker JB, Pothos EN, Seasholtz AF, Thompson RC, Myers MG Jr (2011) Leptin action via neurotensin neurons controls orexin, the mesolimbic dopamine system and energy balance. Cell Metab 14:313-323.

Lowe MR, Butryn ML (2007) Hedonic hunger: a new dimension of appetite? Physiol Behav 91:432-439.

Lowery-Gionta EG, Navarro M, Li C, Pleil KE, Rinker JA, Cox BR, Sprow GM, Kash TL, Thiele TE (2012) Corticotropin releasing factor signaling in the central amygdala is recruited during binge-like ethanol consumption in C57BL/6J mice. J Neurosci 32:3405-3413.

Mahler SV, Berridge KC (2009) Which cue to "want?" Central amygdala opioid activation enhances and focuses incentive salience on a prepotent reward cue. J Neurosci 29:6500-6513.

Malik VS, Pan A, Willett WC, Hu FB (2013) Sugar-sweetened beverages and weight gain in children and adults: a systematic review and meta-analysis. Am J Clin Nutr 98:1084-1102.

McCall JG, Al-Hasani R, Siuda ER, Hong DY, Norris AJ, Ford CP, Bruchas MR (2015) CRH engagement of the locus coeruleus noradrenergic system mediates stress-induced anxiety. Neuron 87:605-620.

McCullough KM, Morrison FG, Hartmann J, Carlezon WA Jr, Ressler KJ (2018) Quantified coexpression analysis of central amygdala subpopulations. eneuro 5:ENEURO.0010-18.2018.

McHenry JA, Otis JM, Rossi MA, Robinson JE, Kosyk O, Miller NW, McElligott ZA, Budygin EA, Rubinow DR, Stuber GD (2017) Hormonal gain control of a medial preoptic area social reward circuit. Nat Neurosci 20:449-458.

Moga MM, Gray TS (1985) Evidence for corticotropin-releasing factor, neurotensin, and somatostatin in the neural pathway from the central nucleus of the amygdala to the parabrachial nucleus. J Comp Neurol 241:275-284.

Möller C, Wiklund L, Sommer W, Thorsell A, Heilig M (1997) Decreased experimental anxiety and voluntary ethanol consumption in rats following central but not basolateral amygdala lesions. Brain Res 760:94-101.

Nie Z, Schweitzer P, Roberts AJ, Madamba SG, Moore SD, Siggins GR (2004) Ethanol augments GABAergic transmission in the central amygdala via CRF1 receptors. Science 303:1512-1514.

Normandeau CP, Torruella Suárez ML, Sarret P, McElligott ZA, Dumont EC (2018) Neurotensin and dynorphin bi-directionally modulate CeA inhibition of oval BNST neurons in male mice. Neuropharmacology 143:113121.

Pleil KE, Rinker JA, Lowery-Gionta EG, Mazzone CM, McCall NM, Kendra AM, Olson DP, Lowell BB, Grant KA, Thiele TE, Kash TL (2015) NPY signaling inhibits extended amygdala CRF neurons to suppress binge alcohol drinking. Nat Neurosci 18:545-552.

Prus AJ, Hillhouse TM, LaCrosse AL (2014) Acute, but not repeated, administration of the neurotensin NTS1 receptor agonist PD149163 decreases conditioned footshock-induced ultrasonic vocalizations in rats. Prog Neuropsychopharmacol Biol Psychiatry 49:78-84.

Robinson MJ, Warlow SM, Berridge KC (2014) Optogenetic excitation of central amygdala amplifies and narrows incentive motivation to pursue one reward above another. J Neurosci 34:16567-16580.

Ryan PJ, Ross SI, Campos CA, Derkach VA, Palmiter RD (2017) Oxytocinreceptor-expressing neurons in the parabrachial nucleus regulate fluid intake. Nat Neurosci 20:1722-1733.

Salling MC, Faccidomo SP, Li C, Psilos K, Galunas C, Spanos M, Agoglia AE, Kash TL, Hodge CW (2016) Moderate alcohol drinking and the amygdala proteome: identification and validation of calcium/calmodulin dependent kinase II and AMPA receptor activity as novel molecular mechanisms of the positive reinforcing effects of alcohol. Biol Psychiatry 79:430-442. 
Schroeder LE, Furdock R, Quiles CR, Kurt G, Perez-Bonilla P, Garcia A, Colon-Ortiz C, Brown J, Bugescu R, Leinninger GM (2019) Mapping the populations of neurotensin neurons in the male mouse brain. Neuropeptides 76:101930.

Scinska A, Koros E, Habrat B, Kukwa A, Kostowski W, Bienkowski P (2000) Bitter and sweet components of ethanol taste in humans. Drug Alcohol Depend 60:199-206.

Sparta DR, Stamatakis AM, Phillips JL, Hovelsø N, van Zessen R, Stuber GD (2011) Construction of implantable optical fibers for long-term optogenetic manipulation of neural circuits. Nat Protoc 7:12-23.

Swanson LW (1976) The locus coeruleus: a cytoarchitectonic, Golgi and immunohistochemical study in the albino rat. Brain Res 110:39-56.

Thiele TE, Roitman MF, Bernstein IL (1996) c-Fos induction in rat brainstem in response to ethanol- and lithium chloride-induced conditioned taste aversions. Alcohol Clin Exp Res 20:1023-1028.
Tye KM, Prakash R, Kim SY, Fenno LE, Grosenick L, Zarabi H, Thompson KR, Gradinaru V, Ramakrishnan C, Deisseroth K (2011) Amygdala circuitry mediating reversible and bidirectional control of anxiety. Nature 471:358-362.

Warlow SM, Robinson MJF, Berridge KC (2017) Optogenetic central amygdala stimulation intensifies and narrows motivation for cocaine. J Neurosci 37:8330-8348.

Yang CF, Chiang MC, Gray DC, Prabhakaran M, Alvarado M, Juntti SA, Unger EK, Wells JA, Shah NM (2013) Sexually dimorphic neurons in the ventromedial hypothalamus govern mating in both sexes and aggression in males. Cell 153:896-909.

Yu K, Garcia da Silva P, Albeanu DF, Li B (2016) Central amygdala somatostatin neurons gate passive and active defensive behaviors. J Neurosci 36:6488-6496. 